\title{
On the Momentum Budget of the Quasi-Biennial Oscillation in the Whole Atmosphere Community Climate Model
}

\author{
ROLANDO R. GARCIA AND JADWIGA H. RICHTER \\ National Center for Atmospheric Research, Boulder, Colorado
}

(Manuscript received 19 March 2018, in final form 20 October 2018)

\begin{abstract}
This study documents the contribution of equatorial waves and mesoscale gravity waves to the momentum budget of the quasi-biennial oscillation (QBO) in a 110-level version of the Whole Atmosphere Community Climate Model. The model has high vertical resolution, $500 \mathrm{~m}$, above the boundary layer and through the lower and middle stratosphere, decreasing gradually to about $1.5 \mathrm{~km}$ near the stratopause. Parameterized mesoscale gravity waves and resolved equatorial waves contribute comparable easterly and westerly accelerations near the equator. Westerly acceleration by resolved waves is due mainly to Kelvin waves of zonal wavenumber in the range $k=1-15$ and is broadly distributed about the equator. Easterly acceleration near the equator is due mainly to Rossby-gravity (RG) waves with zonal wavenumbers in the range $k=4-12$. These RG waves appear to be generated in situ during both the easterly and westerly phases of the QBO, wherever the meridional curvature of the equatorial westerly jet is large enough to produce reversals of the zonal-mean barotropic vorticity gradient, suggesting that they are excited by the instability of the jet. The RG waves produce a characteristic pattern of Eliassen-Palm flux divergence that includes strong easterly acceleration close to the equator and westerly acceleration farther from the equator, suggesting that the role of the RG waves is to redistribute zonal-mean vorticity such as to neutralize the instability of the westerly jet. Insofar as unstable RG waves might be present in the real atmosphere, mixing due to these waves could have important implications for transport in the tropical stratosphere.
\end{abstract}

\section{Introduction}

The quasi-biennial oscillation $(\mathrm{QBO})$ is the principal mode of variability of the tropical stratosphere, from the near-tropopause region at $100 \mathrm{hPa}(16 \mathrm{~km})$ to the upper stratosphere near $3 \mathrm{hPa}(40 \mathrm{~km})$, where the circulation begins to be dominated by the semiannual oscillation (Baldwin et al. 2001). In addition to its role in the dynamics of the deep tropics, eddy and mean meridional circulation transports associated with the QBO are an important source of variability in the chemical composition of the tropics (Shuckburgh et al. 2001; Kawatani et al. 2014; Park et al. 2017); they also modulate transport between the tropics and higher latitudes (Strahan et al. 2015), and may even influence the dynamics of the winter stratosphere (e.g., Holton and Tan 1980; Kodera et al. 1991; Anstey and Shepherd 2014; Kim and Chun 2015a).

The QBO has been difficult to simulate in comprehensive general circulation models, most likely because,

\footnotetext{
Corresponding author: Rolando R. Garcia, rgarcia@ucar.edu
}

until relatively recently, most such models were run with insufficient horizontal and especially vertical resolution, or they lacked an adequate representation of the effects of subgrid-scale gravity waves. Nevertheless, the requirements for a successful simulation of the QBO were convincingly demonstrated more than 15 years ago by Giorgetta et al. (2002): adequate horizontal and vertical resolution, a realistic simulation of tropical convection, and a means of describing the effects of (unresolved) mesoscale gravity waves. The last of these might not be needed when simulations are carried out at very high horizontal resolution $\left(<1^{\circ}\right.$ in latitude and longitude; e.g., Kawatani et al. 2010), although it is arguable that even such models cannot simulate explicitly all of the relevant pseudomomentum flux carried by mesoscale waves (cf. Bergman and Salby 1994). All of the modeling requirements enumerated by Giorgetta et al. (2002), including a parameterization of mesoscale gravity wave driving (e.g., Richter et al. 2010), are present in all recent, successful simulations of the QBO carried out at more moderate horizontal resolution (e.g., Giorgetta et al. 2006; Krismer and Giorgetta 2014; 
Richter et al. 2014b; McCormack et al. 2015; Geller et al. 2016; Anstey et al. 2016).

A consistent finding of these simulations is that at least the westerly, or "West," phase of the oscillation is driven by comparable amounts of forcing from largescale tropical waves and mesoscale gravity waves. The tropical waves that drive the West phase are eastwardpropagating Kelvin waves at periods between a few days and more than 20 days, the slower waves being most important in the lower stratosphere, where they are instrumental in the downward propagation of the West phase to the tropical tropopause, near $100 \mathrm{hPa}$ (e.g., Richter et al. 2014b). The role of westwardpropagating waves is less clear. Such waves, in particular mixed Rossby-gravity (RG) waves, were proposed as a mechanism for driving the easterly, or "East," phase of the QBO over 45 years ago by Holton and Lindzen (1972), and it is clear that they are excited by tropical convection in numerical models and can be simulated given sufficient vertical resolution, but their role in driving the East phase remains uncertain. High horizontal resolution simulations (e.g., Kawatani et al. 2010) suggest that RG waves provide no more than $\sim 10 \%$ of the acceleration in the QBO East phase, whereas the contribution of Kelvin waves to the West phase can be as large as $50 \%$.

In the present study, we document the contributions of different waves to the momentum budget of the QBO in a 110-level version of the Whole Atmosphere Community Climate Model (WACCM), described in section 2 . The model contains the same parameterization of mesoscale gravity waves used in previous versions but has updated physics and, most important, high vertical resolution of $500 \mathrm{~m}$ between the top of the boundary layer and about $10 \mathrm{hPa}$. As previously noted by Richter et al. (2014b), high vertical resolution is needed to produce a QBO that reaches the lowermost stratosphere. The global climatology produced by the model is documented briefly in section 3 , where it is shown that the enhanced vertical resolution throughout the troposphere, and lower and middle stratosphere, produces a simulation that has relatively minor biases with respect to ERA-Interim, and that the internally generated QBO also agrees well with that deduced from the reanalysis.

The role of waves in the momentum budget of the model is discussed in detail in section 4, where the relative contributions of explicitly resolved equatorial waves and parameterized gravity waves are discussed, and the equatorial waves that contribute to the momentum budget are identified. As expected from theory and previous work, Kelvin waves over the range of wavenumber $k=1-15$ contribute substantially to the descending West phase of the QBO. On the other hand, there is no clear evidence in the simulation that $\mathrm{RG}$ waves propagating from the troposphere are significant contributors to the momentum budget of the East phase. Instead, we find that RG waves at wavenumbers $k=4-12$ appear to be generated in situ in connection with the barotropic instability of the QBO westerly jet; the waves are excited whenever the meridional profile of the QBO westerlies is sufficiently narrow and are thus present in both the descending East and West phases of the simulated QBO. A summary and discussion of our findings is presented in the last section.

\section{Numerical model}

\section{a. Model description}

WACCM is a "high top" model that is used here as the atmospheric component of the Community Earth System Model, version 1 (CESM1; Hurrell et al. 2013). The tropospheric physics and parameterizations in this version of WACCM are based on the Community Atmosphere Model, version 5 (CAM5), which has been described in detail by Mills et al. (2017). WACCM includes a comprehensive chemical scheme as well as updated physical parameterizations for planetary boundary layer turbulence, cloud microphysics, and aerosols. The horizontal resolution is $0.95^{\circ} \times 1.25^{\circ}$ (latitude $\times$ longitude). For this study, we have modified the model by increasing the number of vertical levels to 110 , instead of the standard 70 levels. The vertical resolution is $500 \mathrm{~m}$ above the boundary layer and through the lower stratosphere, and then decreases slowly with altitude as shown in Fig. 1, where it is compared to the vertical resolution of the standard version. The model top is located at $6 \times 10^{-6} \mathrm{hPa}$ (approximately $140-\mathrm{km}$ geometric altitude). Throughout the remainder of the paper we refer to this version of CESM1(WACCM) as WACCM-110L.

Model physics in WACCM-110L are the same as in the standard, 70-level version described by Mills et al. (2017), with only slight differences in the values assigned to certain parameters in the gravity wave parameterizations. WACCM-110L includes a nonorographic gravity wave parameterization following Richter et al. (2010), which describes separately nonorographic wave sources due to fronts and convection. The dissipation of the parameterized gravity waves uses Lindzen's (1981) "saturation" formulation. As discussed in detail by Richter et al. (2010), frontally generated waves are launched when a frontogenesis function (Hoskins 1982) exceeds a specified critical value, and convectively generated gravity waves are launched in regions where the deep convection scheme of Zhang and McFarlane (1995) is 


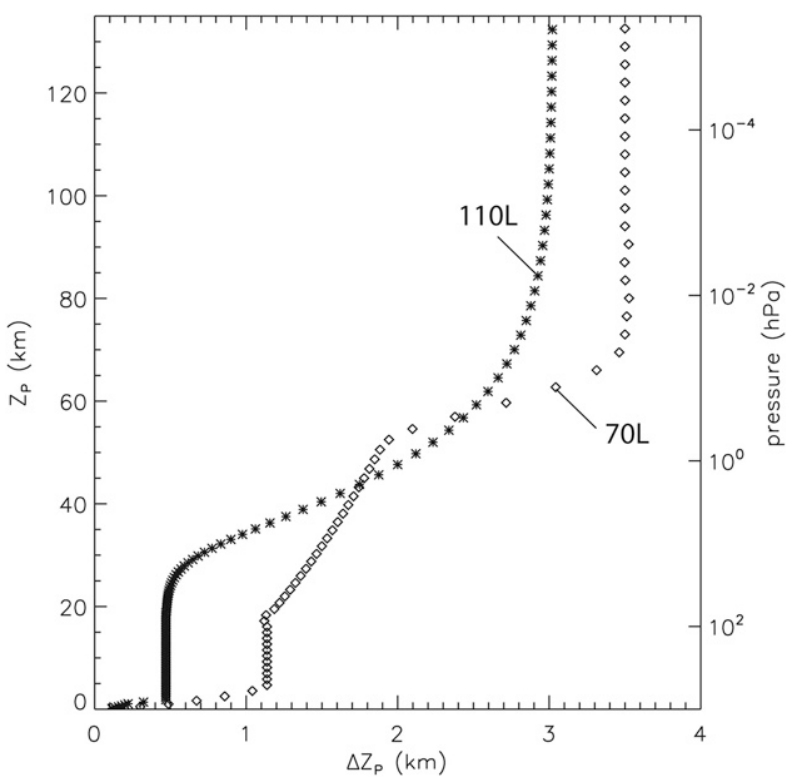

FIG. 1. Approximate vertical grid spacing $\Delta Z_{P}$ as a function of $\log$ pressure altitude $Z_{P}$ in WACCM-110L compared to the standard-resolution, 70-level model.

triggered. The momentum flux phase speed spectrum of these waves is calculated using the method of Beres et al (2005), which is based on the depth of the convective heating and the mean wind within the heating region. In WACCM-110L, we use a frontogenesis threshold of $3 \times 10^{-15} \mathrm{~K}^{2} \mathrm{~m}^{-2} \mathrm{~s}^{-1}$, and an amplitude of frontally generated gravity waves of $2.5 \times 10^{-3} \mathrm{~Pa}$, the same as in the 70-level model. The efficiency of the convectively generated gravity waves is set to 0.475 .

WACCM-110L includes an interactive middleatmospheric chemistry package based on the Model for Ozone and Related Chemical Tracers (MOZART3; Kinnison et al. 2007). All reaction rate constants are taken from Sander et al. (2006). The land, ocean, and sea ice components of CESM1(WACCM-110L) are the Community Land Model, version 4.0 (CLM4.0; Lawrence et al. 2011), the Parallel Ocean Program, version 2 (POP2; Danabasoglu et al. 2012), and the Los Alamos Sea Ice Model (CICE 25, version 4; Holland et al. 2012). Optionally, the model may be run with prescribed chemistry and sea surface temperatures.

\section{b. Simulation setup}

The results discussed here were obtained from a simulation of the period 1975-2015 run with prescribed sea surface temperatures and sea ice. We have specified these fields from the AMIP dataset (https://pcmdi.llnl. gov/mips/amip/), originally described by Taylor et al. (2000). The model is run with interactive chemistry, so there is no need to specify ozone or other radiatively active gases, whose distributions are computed as part of the simulation. The model does require boundary conditions for gases emitted at the surface, and for these we use observed surface mixing ratios, extended past 2005 according to representative concentration pathway 8.5 [RCP8.5; see Moss et al. (2010) and Meinshausen et al. (2011)]. While the model produces a full set of chemical outputs, these are not discussed in the present study, which focuses on the momentum budget of the simulated QBO.

\section{Model climatology}

\section{a. Global climatology}

Before discussing the behavior of the QBO in WACCM-110L, we review briefly the salient features of the model climatology to show that the increase in vertical resolution produces a simulation that compares as well to climatological observations as the simulation documented by Mills et al. (2017) using the default 70-level model. Figures 2 and 3 illustrate the climatological distributions of zonal-mean temperature and zonal wind averaged over the solstice seasons [December-February (DJF) and June-August (JJA)], and their differences with respect to the ERA-Interim (ERAI) climatology (Dee et al. 2011). These differences are shown only below $50 \mathrm{~km}$, where ERAI data are available.

The largest differences with respect to ERAI occur in the upper stratosphere in winter (Southern Hemisphere in JJA and Northern Hemisphere in DJF) and are associated with the winter polar night jet, which is stronger in WACCM-110L than in ERAI. In DJF all differences are small, reaching maxima of a little over $10 \mathrm{~m} \mathrm{~s}^{-1}$ in zonal wind near $60^{\circ} \mathrm{N}$ and $1 \mathrm{hPa}$ (Fig. 2c), and $\pm 4 \mathrm{~K}$ in temperature (Fig. 3c). The temperature biases appear as a dipole flanking the zonal wind bias, as expected from thermal wind balance, such that there is a warm bias centered at $45^{\circ} \mathrm{N}$ and a cold bias centered over the northern polar cap. In JJA a similar pattern of differences is seen near $60^{\circ} \mathrm{S}$, except that the biases are about twice as large as in DJF (Figs. 2d and 3d). As in northern winter, the largest southern winter differences in the zonal-mean zonal wind $\left(20 \mathrm{~m} \mathrm{~s}^{-1}\right)$ arise from too strong a polar night jet and are flanked by a dipole pattern of zonal-mean temperature differences $( \pm 8 \mathrm{~K})$. In addition to these extratropical biases, there are also small differences in zonal wind and temperature in the deep tropics. Statistical significance is not indicated explicitly in Figs. 2 and 3. However, absolute differences in zonal wind greater than $4-5 \mathrm{~m} \mathrm{~s}^{-1}$ are generally significant during winter and differences greater than $2 \mathrm{~m} \mathrm{~s}^{-1}$ 

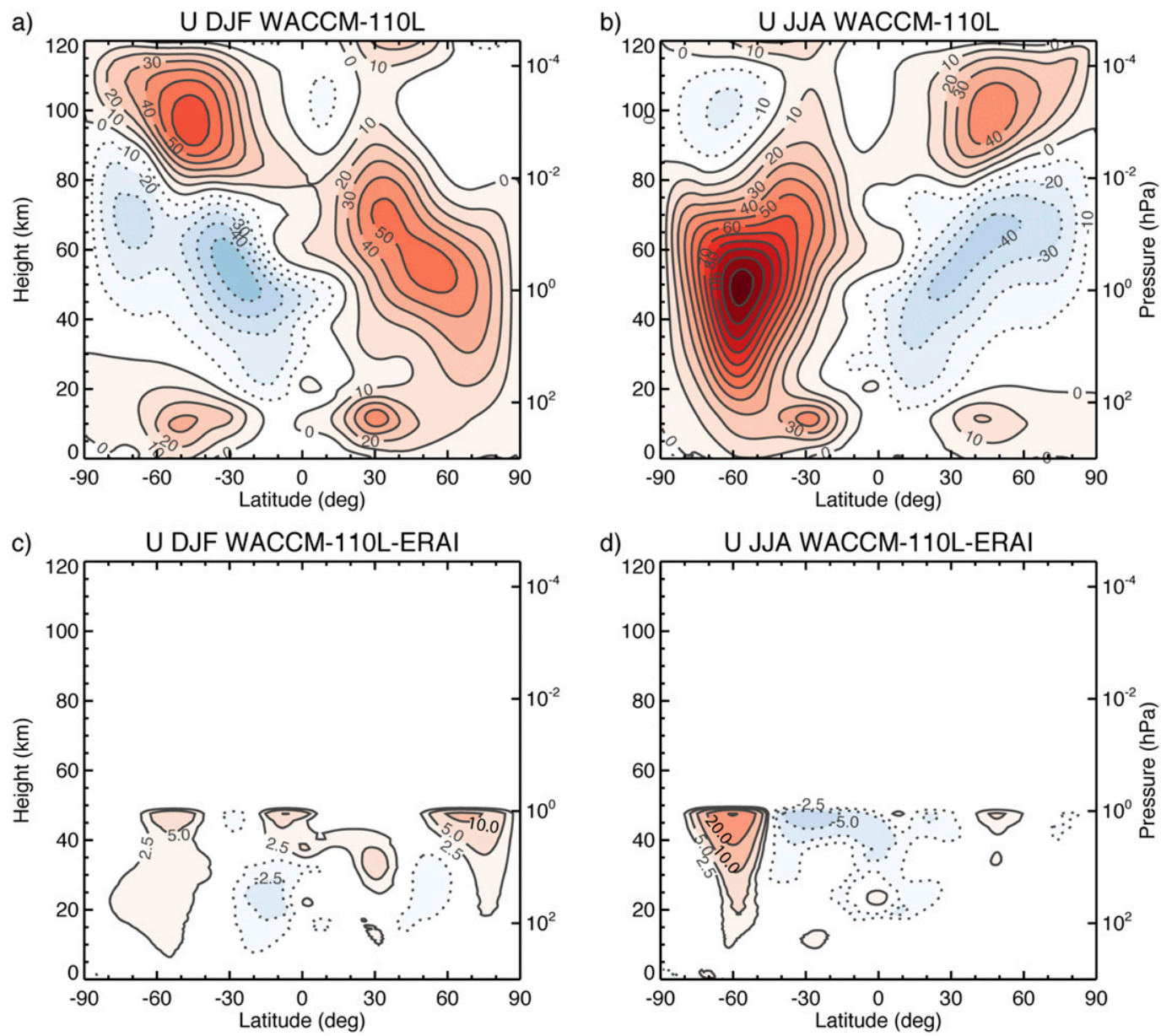

FIG. 2. Zonal-mean zonal wind ( $\mathrm{m} \mathrm{s}^{-1}$ ) climatology (1980-2010) for (a) DJF and (b) JJA, and (c),(d) the respective differences with respect to ERA-Interim. Contour intervals in (a) and (b) are $10 \mathrm{~m} \mathrm{~s}^{-1}$. In (c) and (d) contours are drawn at $0, \pm 2.5, \pm 5, \pm 10$, and $\pm 20 \mathrm{~m} \mathrm{~s}^{-1}$. See text for details.

are significant in summer; the corresponding values for temperature are $2-3$ and $1 \mathrm{~K}$. In the deep tropics, where variability associated with the QBO and SAO is considerable at all times, absolute differences of $3 \mathrm{~K}$ in temperature are significant. Therefore, most of the extratropical differences shown in Figs. 2 and 3 are significant, while in most of the tropics the simulation is not significantly different from ERAI.

Overall, the climatological biases present in WACCM$110 \mathrm{~L}$ are comparable to or smaller than those found by Mills et al. (2017) in the 70-level version of the model. Thus, the increased vertical resolution throughout the troposphere and lower stratosphere preserves the extratropical climatology of the 70-level model while producing a realistic QBO, as shown below. We note also that the increased vertical resolution improves the near-tropopause cold biases present in the 70-level model by about $50 \%$, consistent with the findings of Richter et al. (2014a).

\section{b. Simulation of the $Q B O$}

We turn now to documenting the behavior of the simulated QBO. Figure 4 shows the evolution of the near-equatorial zonal-mean zonal wind in monthly mean model output compared with monthly mean data from ERAI over the period January 1980-January 2000. The behavior of the QBO does not change appreciably over the entire span of the simulation (1975-2015, inclusive); we display the shorter time span 1980-2000 to enhance the readability of the plots. The output from WACCM-110L has been averaged over latitudes $\pm 2.36^{\circ}$, which corresponds to three grid cells on either side of the equator. ERAI data are averaged over $\pm 2.45^{\circ}$. The model is in good agreement with observations as regards the period and overall morphology of the oscillation, although both the East and West phases have somewhat larger amplitudes in WACCM-110L than in the reanalysis. The duration of the West phases 
a)

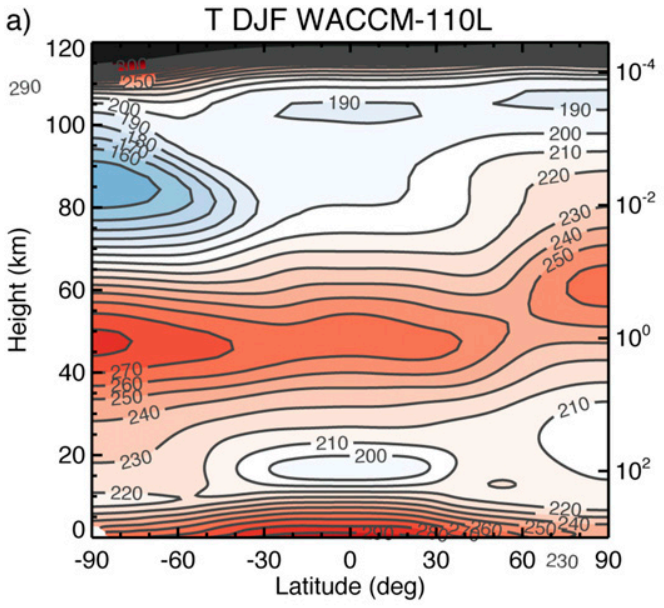

c)

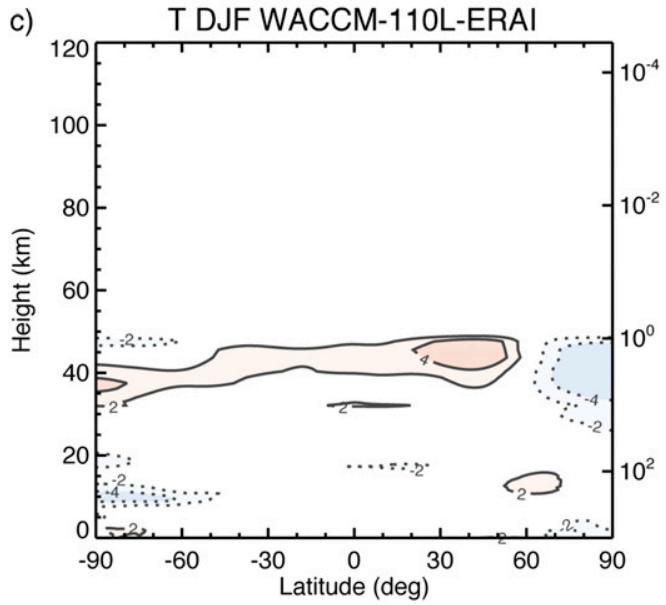

b)

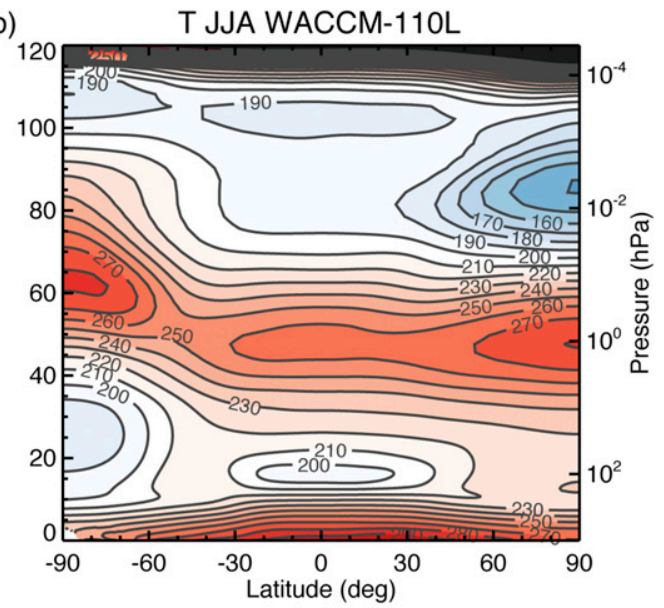

d)

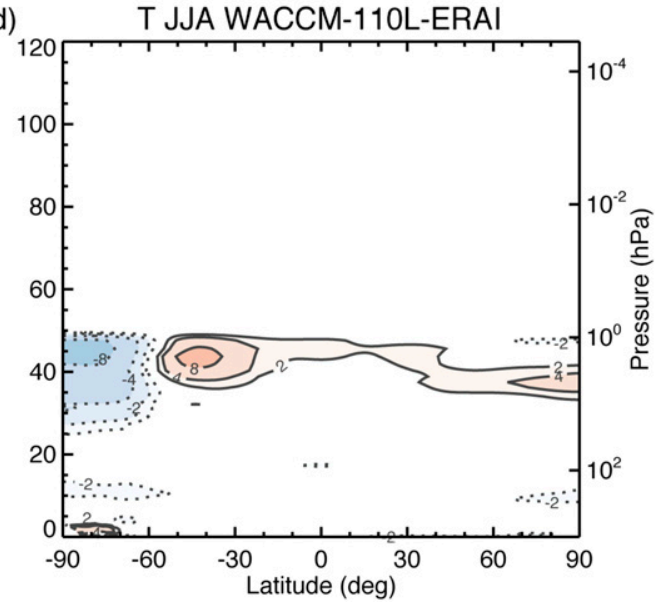

FIG. 3. As in Fig. 2, but for zonal-mean temperature (K). (a),(b) Contour intervals are 10 K. (c),(d) Contours are drawn at $0, \pm 2, \pm 4$, and $\pm 8 \mathrm{~K}$.

is short in the upper stratosphere and longer in the lower stratosphere, while the opposite is true of the East phases, as seen also in ERAI data. The connection with the stratopause semiannual oscillation (SAO) is evident in both the model and the data, in particular the deeper descent of the stratopause SAO westerlies when the QBO is in the West phase in the upper stratosphere, behavior that has been known for some time (e.g., Dunkerton and Delisi 1997; Garcia et al. 1997).

The period of the simulated QBO is 27.5 months, which compares very well with the observed period of 28 months. Differences between the structure of the QBO in WACCM-110L and ERAI can be appreciated in more detail from Fig. 5, which shows the latitudealtitude structure of the zonal wind QBO obtained from a coherence analysis (Hayashi 1971) over the frequency band $0.025-0.05$ cycles per month, which corresponds to periods of 40-20 months. This band was chosen from inspection of the near-equatorial power spectra from WACCM-110L and ERAI, both of which exhibit a single, large spectral peak in this band (not shown). The spectra, cospectra, and quadrature spectra of the zonal-mean zonal wind are smoothed with a three-point boxcar average before computing the coherence squared and the amplitude and phase of the oscillation. Significance is based on the resulting 6 degrees of freedom per spectral component. Figure 5 shows that the structure of the simulated QBO is remarkably similar to that derived from ERAI, except that the amplitude is larger than observed, although the difference is nowhere larger than $\sim 5 \mathrm{~m} \mathrm{~s}^{-1}$ (about $20 \%$ ). The phase progression, especially at altitudes between 20 and $40 \mathrm{~km}$, is remarkably well simulated, as is the meridional width of the oscillation. In both WACCM-110L and ERAI, the coherent oscillation is significant at the 95\% level (Julian 1975) within about $\pm 20^{\circ}$ of the equator and from the tropopause to the upper stratosphere. 

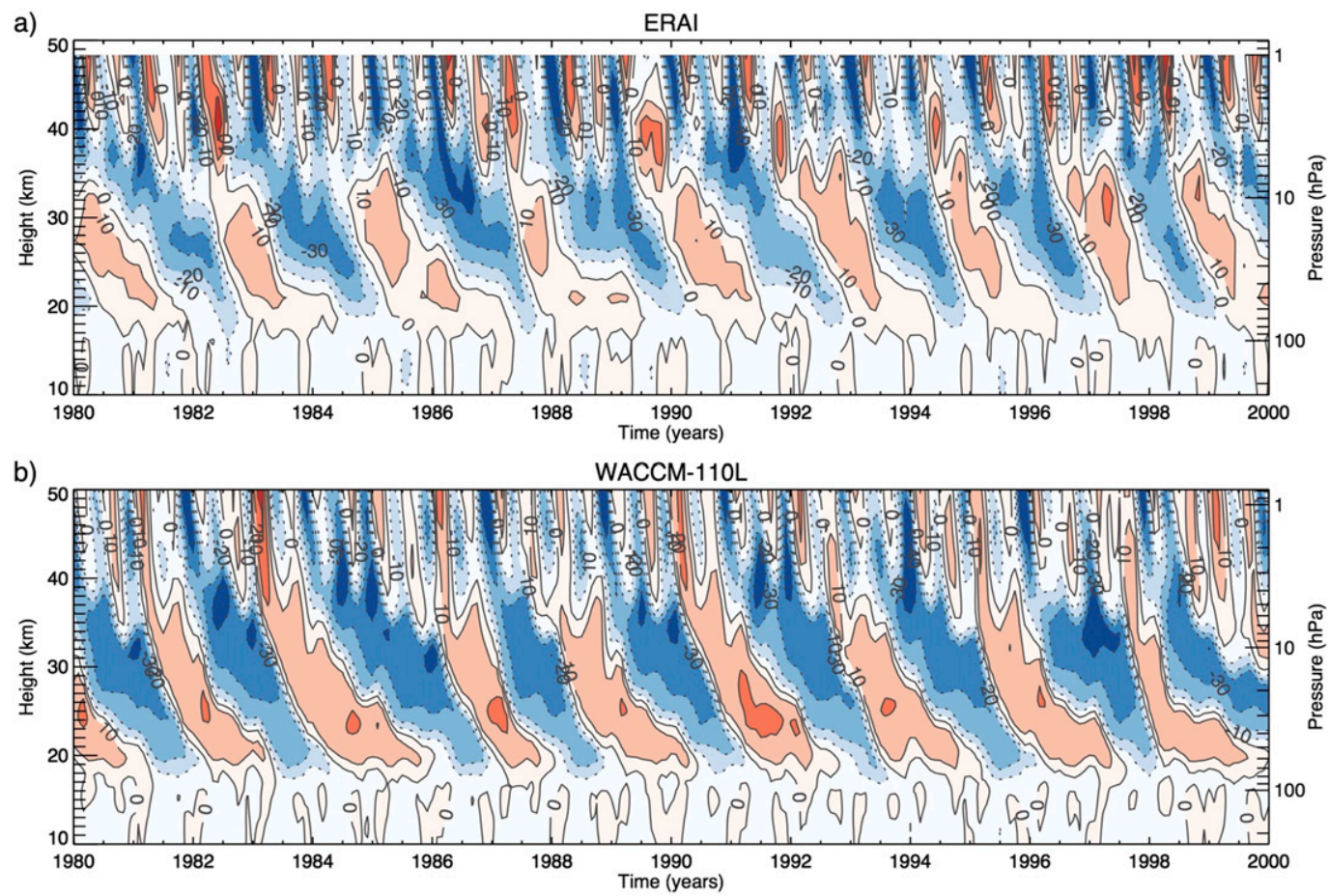

FIG. 4. (bottom) Zonal-mean zonal wind $\left(\mathrm{m} \mathrm{s}^{-1}\right.$ ) averaged over $\pm 2.36^{\circ}$ in WACCM-110L, compared with (top) data from ERAI averaged over $\pm 2.45^{\circ}$ for the period $1980-2000$.

\section{Momentum budget of the simulated QBO}

\section{a. Evolution at the equator}

The top two panels in Fig. 6 show the evolution of zonal-mean acceleration due to resolved waves and parameterized mesoscale gravity waves that drive the simulated QBO throughout the stratosphere. The acceleration due to the resolved waves is proportional to the divergence of the Eliassen-Palm (EP) flux, whose components are calculated in log pressure coordinates (a) WACCM

Amp, Phi: $(0.050,0.025) \mathrm{cpm} 1980-2010$

sig: $95 \%$, bp: $\left(-0.5^{\circ}, 14.1 \mathrm{hPo}\right)$,

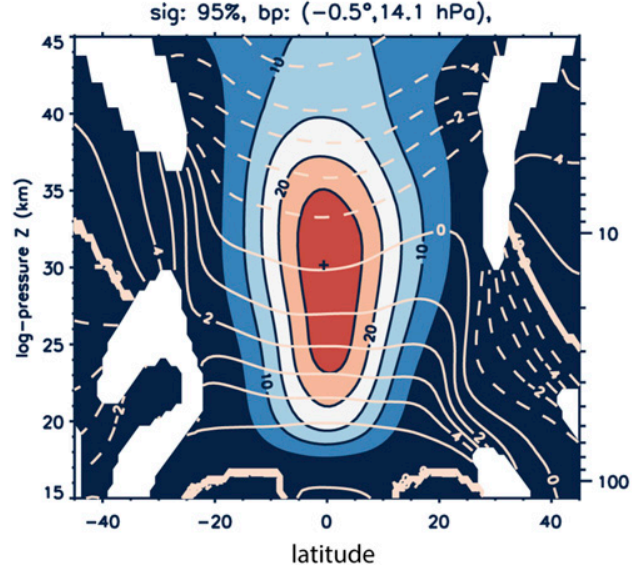

(b) ERA-Interim

Amp, Phi: $(0.050,0.025) \mathrm{cpm} 1980-2010$ sig: $95 \%$, bp: $\left(0.0^{\circ}, 15.2 \mathrm{hPa}\right)$,

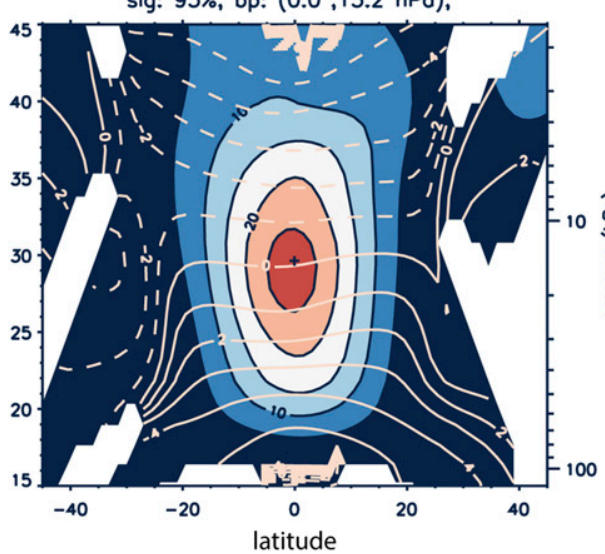

FIG. 5. Amplitude ( $\mathrm{m} \mathrm{s}^{-1}$ ) and phase (months) of the QBO in (a) WACCM-110L and (b) ERAI calculated over the frequency band of $0.025-0.05$ cycles per month (periods of 40-20 months). Results are omitted where the significance of the coherence-squared statistic is $<95 \%$. See text for details. The base point for the coherence analysis is denoted by the plus sign in each panel. 

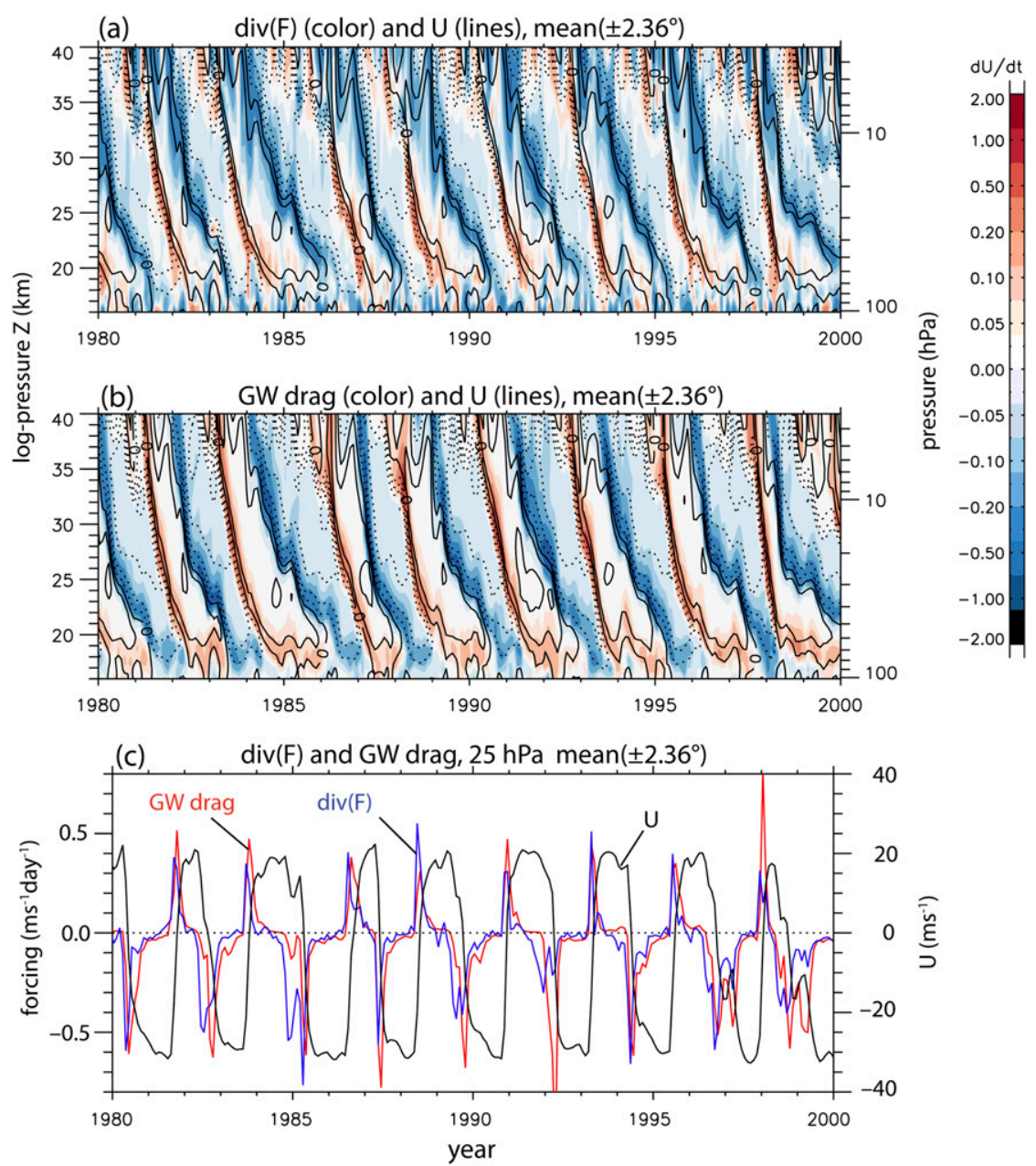

FIG. 6. Evolution of the acceleration $\left(\mathrm{m} \mathrm{s}^{-1}\right.$ day $\left.^{-1}\right)$ due to (a) divergence of the EP flux of resolved waves and (b) parameterized GW drag, both averaged within $2.36^{\circ}$ of the equator in WACCM-110L. The zonal-mean zonal wind is superimposed as line contours with an interval of $10 \mathrm{~m} \mathrm{~s}^{-1}$. The contour intervals of the color scale are variable to allow visualization of the weak accelerations away from the shear zones. (c) The zonal-mean zonal wind $\left(\mathrm{m} \mathrm{s}^{-1}\right)$ together with the accelerations at $25 \mathrm{hPa}$.

according to Eqs. (3.5a) and (3.5b) in Andrews et al. (1987). The plot uses monthly mean model output over a 20 -yr segment of the simulation: January 1980January 2000. The acceleration is shown on a blue to red color scale covering $\pm 2 \mathrm{~m} \mathrm{~s}^{-1}$ day $^{-1}$, with nonuniform contour spacing so the weaker acceleration away from the shear zones can be more easily appreciated. Zonal-mean wind contours are superimposed on the acceleration to show the relationship between the two.

Two properties of the simulated QBO are immediately evident: contributions to the zonal-mean acceleration from the EP flux of resolved waves and from parameterized gravity wave drag are of comparable magnitude in the near-equatorial average used here, and the acceleration is concentrated along the westerly and easterly shear zones, especially in the case of westerly acceleration. This is broadly consistent with results from other general circulation models where mesoscale gravity wave drag is parameterized (Giorgetta et al. 2002, 2006; McCormack et al. 2015; Anstey et al. 2016), and also in models with very high horizontal resolution (Hamilton et al. 2001; Kawatani et al. 2010), where waves of short horizontal wavelength are modeled explicitly and no gravity wave parameterization is used. However, most of these studies conclude that easterly forcing due to resolved EP flux divergence is small (e.g., Giorgetta et al. 2002; Kawatani et al. 2010). In WACCM-110L, near-equatorial easterly acceleration by resolved waves is not negligible.

These and other features of the evolution of wave forcing can be appreciated in more detail in Fig. 6c, 
which shows the accelerations due to resolved EP flux divergence and gravity wave drag at $25 \mathrm{hPa}$, and its relationship to the zonal-mean zonal wind. At this level, the magnitude of the near-equatorial acceleration due to EP flux divergence is as large or larger during the East phase as during West phase (and both are comparable to the magnitude of the GW drag). It is also clear from Fig. 6c that intervals of westerly acceleration due to EP flux divergence are sharply confined to the times when the zero-wind line descends through the $25-\mathrm{hPa}$ level. Easterly accelerations are more broadly spread with respect to the descending zero-wind line, consistent with the findings of Kawatani et al. (2010), although we note again that in WACCM-110L parameterized GW and resolved waves contribute approximately equal easterly accelerations.

Our results can also be compared to observational studies of the QBO momentum budget. For example, Alexander and Ortland (2010) estimated that about half of the acceleration in the West phase at pressure levels $10-14 \mathrm{hPa}$, averaged over latitudes $\pm 5^{\circ}$, is due to Kelvin waves and has a typical magnitude of about $0.5 \mathrm{~m} \mathrm{~s}^{-1}$ day $^{-1}$. At lower levels, 20-25 hPa, Alexander and Ortland found accelerations of $0.2 \mathrm{~m} \mathrm{~s}^{-1} \mathrm{day}^{-1}$. Similarly, Ern and Preusse (2009a,b) and Ern et al. (2014) obtained westerly accelerations of $0.1-0.5 \mathrm{~m} \mathrm{~s}^{-1}$ day $^{-1}$ between 15 and $60 \mathrm{hPa}$ (averaged over the latitude range $\pm 2^{\circ}$ in the earlier studies and over $\pm 10^{\circ}$ in the latter). These values are generally consistent with what is shown in Fig. 6c (at $25 \mathrm{hPa}$ ), and we confirm below (section $4 \mathrm{~d}$ ) that the westerly acceleration is indeed due to Kelvin waves over a broad range of wavenumbers. On the other hand, for the East phase of the QBO, Ern et al. (2014) concluded that equatorial waves make minor contributions to the accelerations in the lower stratosphere, below $\sim 10 \mathrm{hPa}$. This is consistent with the findings of Kawatani et al. (2010) and others from numerical models, and again contrary to what we calculate with WACCM-110L (cf. Fig. 6c). Somewhat different results were obtained by Kim and Chun (2015b) using data from various modern reanalyses. Kim and Chun estimated that Kelvin waves contribute accelerations of about 2-6 $\mathrm{m} \mathrm{s}^{-1}$ month $^{-1}\left(\sim 0.07-0.21 \mathrm{~m} \mathrm{~s}^{-1} \mathrm{day}^{-1}\right)$ to the West phase of the QBO at $30 \mathrm{hPa}$, in line with the values from other studies. For westward-propagating RG and inertia-gravity (IG) waves together in the East phase, Kim and Chun obtained accelerations from -1 to $-2 \mathrm{~m} \mathrm{~s}^{-1}$ month $^{-1}\left(-0.03\right.$ to $-0.07 \mathrm{~m} \mathrm{~s}^{-1}$ day $\left.^{-1}\right)$. Thus, in Kim and Chun's estimates, easterly forcing by RG and IG waves is not as small as has been found in other studies, but still only about one-third as large as westerly forcing by Kelvin waves.

\section{b. Descending West and East phase composites}

The latitude-altitude distribution of the wave forcing of the simulated QBO is an interesting aspect of the oscillation that cannot be appreciated by considering only the evolution of EP flux divergence and GW drag averaged about the equator. To address this point, Fig. 7 shows the distribution of these quantities, and their sum, for "descending West phase" and "descending East phase" composites. These composites are constructed from monthly mean output by averaging the accelerations for the month when a descending West or East phase reaches a reference level, here taken to be $30 \mathrm{hPa}$ (about 25-km log pressure altitude).

Figures $7 \mathrm{a}-\mathrm{c}$ show results for the descending West phase, and Figs. 7d-f for the descending East phase. During the descending West phase, both EP flux divergence and $\mathrm{GW}$ drag occur over a broad arc centered on the equator and extending to about $\pm 15^{\circ}$ at increasingly higher altitudes, along the region of maximum westerly shear. In the descending East phase, GW drag is again distributed broadly about the equator, coincident with the region of largest easterly shear; however, the distribution of EP flux divergence has fine meridional structure, with a region of easterly forcing confined within $\pm 5^{\circ}$ of the equator flanked by regions of westerly forcing centered approximately $10^{\circ}$ north and south of the equator. Note that the fine structure of the easterly acceleration due to EP flux divergence in the descending East phase could cause easterly forcing by resolved waves to be overlooked when the forcing is averaged over a latitude band broader than about $5^{\circ} \mathrm{S}-5^{\circ} \mathrm{N}$, and this might be a reason for the apparent discrepancy between the present results and those reported by other authors. We discuss this possibility in more detail below. Note also that, in both phases of the QBO, the total wave forcing (Figs. 7c,f) is much smoother in latitude than the forcing due to either EP flux divergence or GW drag individually. This is consistent with the spirit of Cohen et al.'s $(2013,2014)$ arguments about "compensation" between different types of wave forcing.

\section{c. Spectral decomposition of the EP flux divergence}

We explore next the nature of the resolved waves that force the East and West phases of the simulated QBO by considering the spectral distribution of acceleration in months when the West and East phases are descending through the middle stratosphere. This analysis uses daily model output in log pressure coordinates for all of the dynamical variables, such that EP flux spectral distributions in frequency and wavenumber can be computed over 1 month, with a frequency bandwidth of 0.033 day $^{-1}$. 
(a) Desc W $\operatorname{div}(F)$

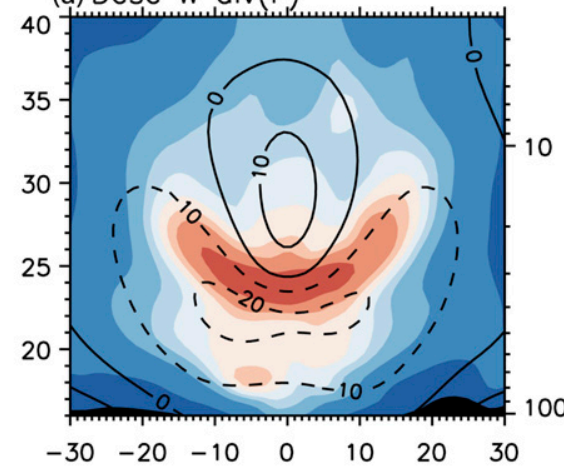

(b)Desc W GW drag

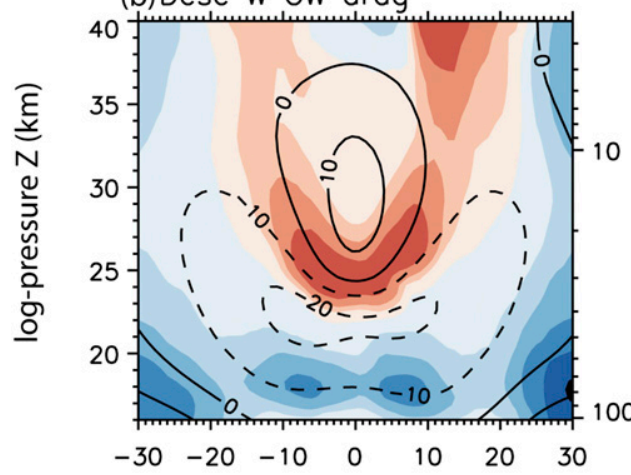

(c) Desc W total

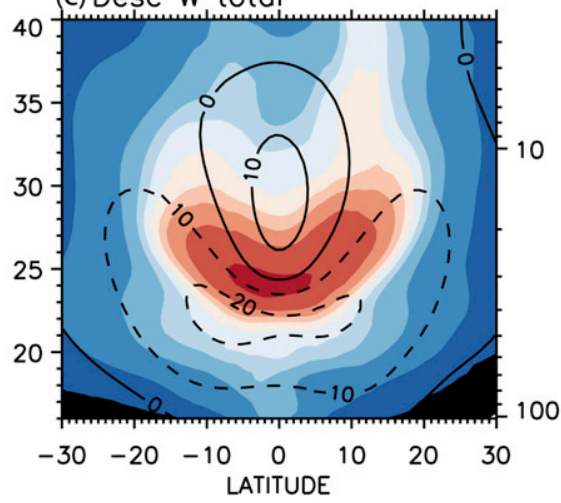

(d)Desc $E \operatorname{div}(F)$

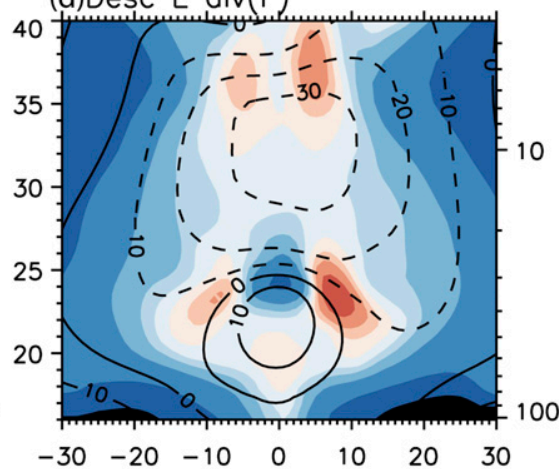

(e)Desc E GW drag
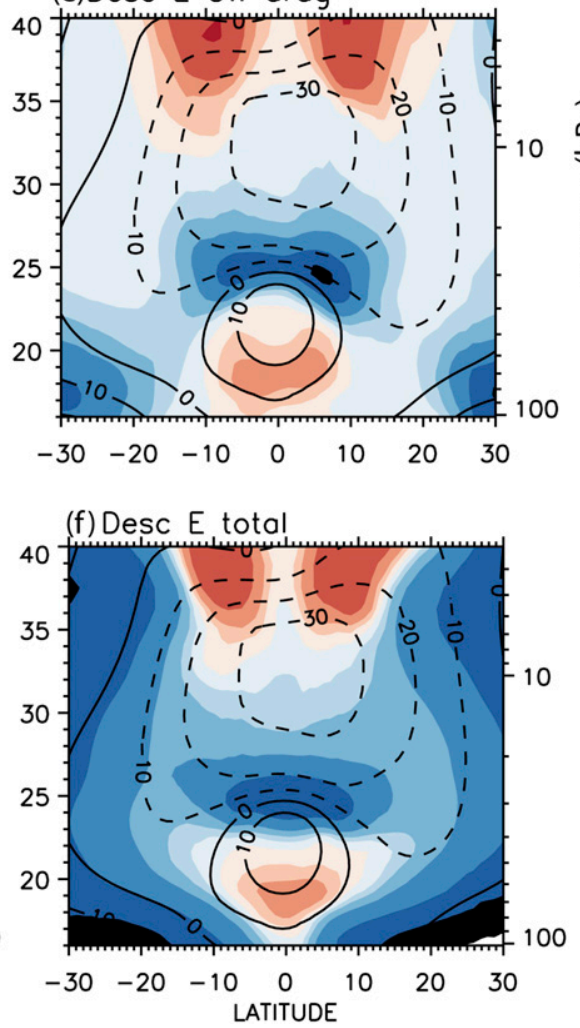

FIG. 7. Composites of acceleration $\left(\mathrm{m} \mathrm{s}^{-1} \mathrm{day}^{-1}\right.$ ) due to (a) EP flux divergence, (b) parameterized GW drag, and (c) their sum during the descending West phase of the QBO in WACCM-L110 (color shading). (d)-(f) As in (a)-(c), but for the descending East phase. Descending West and East phases are defined with respect to the month when westerly and easterly winds, respectively, reach the 30 -hPa pressure level. Composite zonal-mean zonal wind distributions (solid contours every $10 \mathrm{~m} \mathrm{~s}^{-1}$ ) are superimposed in each panel. Note the variable contour intervals in the color scale for the acceleration.

We chose the months of April 1993 and April 1994 from the WACCM-110L simulation, when successive descending West and East phases happened to reach the 20-30-hPa pressure range in the middle stratosphere. Other descending West and East phases were examined; the results shown here are typical of those phases as well and, indeed, typical of what happens at other levels in the stratosphere.
To calculate the spectral EP flux divergence, daily, three-dimensional temperature and velocity fields are Fourier transformed in wavenumber and frequency, and the results are used to compute the eddy fluxes from which the EP fluxes and their divergence are constructed [see Calvo and Garcia (2009) for details]. The spectrally decomposed accelerations are shown in Fig. 8 at $22 \mathrm{hPa}$, truncated at zonal wavenumber $k=20$. Note, however, 


\section{$\operatorname{div}(\mathbf{F})$ spectral density $\left(\mathrm{ms}^{-1}\right.$ day $^{-1} /$ day $\left.^{-1} \mathrm{wno}^{-1}\right)$}

$27 \mathrm{~km}(22 \mathrm{hPa})$; mean $\pm 5.2^{\circ}$

(a) April 1993

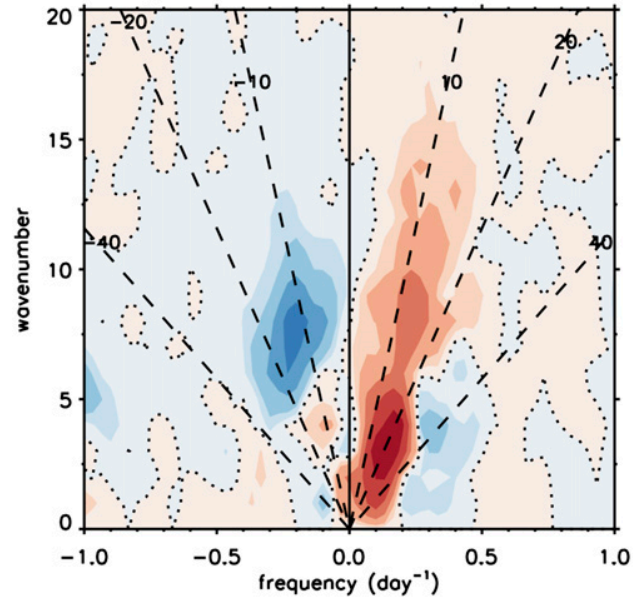

(b) April 1994

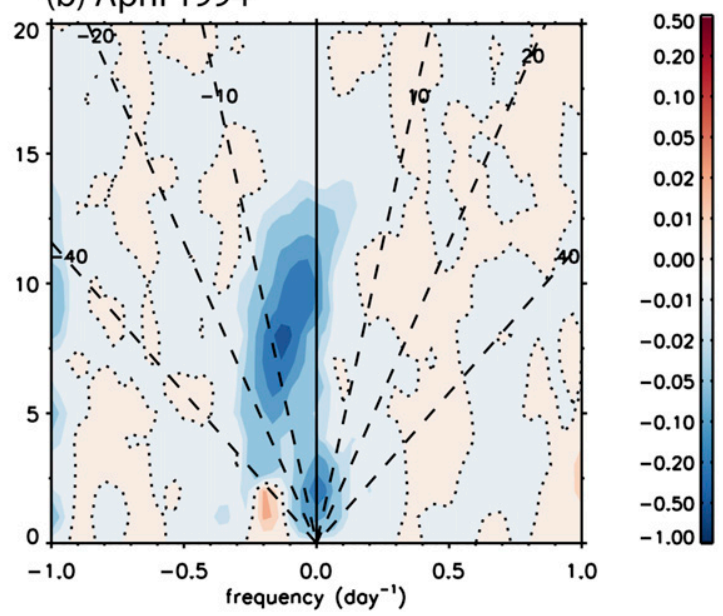

FIG. 8. Spectral decomposition of the acceleration due to EP flux divergence during (a) the descending West phase of April 1993 and (b) the descending East phase of April 1994 within $\pm 5^{\circ}$ latitude. Positive frequencies correspond to eastward-propagating waves and negative frequencies to westward-propagating waves. Dashed lines denote constant phase velocities $c=\omega / k$ of $\pm 10, \pm 20$, and $\pm 40 \mathrm{~m} \mathrm{~s}^{-1}$. The color scale for the acceleration has variable contour intervals.

that the analysis was carried out for wavenumbers up to $k=50$, which corresponds to the estimated shortest wavelength $(\sim 800 \mathrm{~km})$ that is well represented in the model after explicit "hyperdiffusion" and implicit numerical diffusion are taken into account. For the descending West phase (Fig. 8a), the majority of the acceleration is due to eastward-propagating waves of zonal wavenumbers $k=1-10$, although there are nonnegligible accelerations at even higher wavenumbers, up to about $k=15$. The strongest accelerations lie in the wavenumber-frequency region that corresponds to phase velocities of $10-30 \mathrm{~m} \mathrm{~s}^{-1}$, which is consistent with the results of Kawatani et al. (2010, their Fig. 2c) at similar altitudes. Interestingly, during the descending West phase there are also accelerations associated with westward-traveling waves in the range of $k=4-12$, centered on $k=8$, at frequencies corresponding to phase velocities from approximately -5 to $-20 \mathrm{~m} \mathrm{~s}^{-1}$.

The contributions of the westward- and eastwardpropagating waves identified in Fig. 8a to the momentum budget of the descending West phase are shown in Figs. 9a and 9b averaged over the month of April 1993; the monthly averaged zonal-mean wind is superimposed as line contours to show the relationship between the accelerations and the descending westerly shear zone. For the eastward-traveling waves, we see a broad arc of acceleration, centered on the equator and extending to higher latitudes and altitudes, similar to the pattern that characterizes the West phase composite of Fig. 7a, but more strongly peaked near the equator. The westwardpropagating waves (Fig. 9b) display a pattern of acceleration similar to that found in the descending East phase composite (Fig. 7b), but here occurring on the bottom side of the descending westerly jet. Because the acceleration due to the westward-propagating waves is weaker than that due to the eastward-propagating waves in the descending West phase, the contribution of the former is masked when the total acceleration for the descending West phase is displayed, as in the composite of Fig. 7a. The acceleration due to the westward-propagating waves opposes that of the eastward-propagating waves very near the equator and reinforces it away from the equator, leading to an overall westerly acceleration pattern that is latitudinally smoother in Fig. 7a compared to Fig. 9a.

In the descending East phase, virtually all of the acceleration due to EP flux divergence is contributed by westward-traveling waves in the range of $k=4-12$, and centered on $k=8$, as in the West phase (Fig. 8b). ${ }^{1}$ These waves are now present at frequencies corresponding

\footnotetext{
${ }^{1}$ There is also some easterly forcing centered on zero frequency and $k=2$, which is associated with quasi-stationary Rossby waves. We are aware that such forcing has been implicated in the disruption of the West cycle of the QBO in 2016 near $40 \mathrm{hPa}$ (e.g., Osprey et al. 2016; Coy et al. 2017). However, Rossby wave forcing does not contribute substantially to the QBO near the equator in the present simulation and is not discussed further here.
} 
acceleration due to $\operatorname{div}(\mathrm{F})\left(\mathrm{ms}^{-1} \mathrm{day}^{-1}\right)$

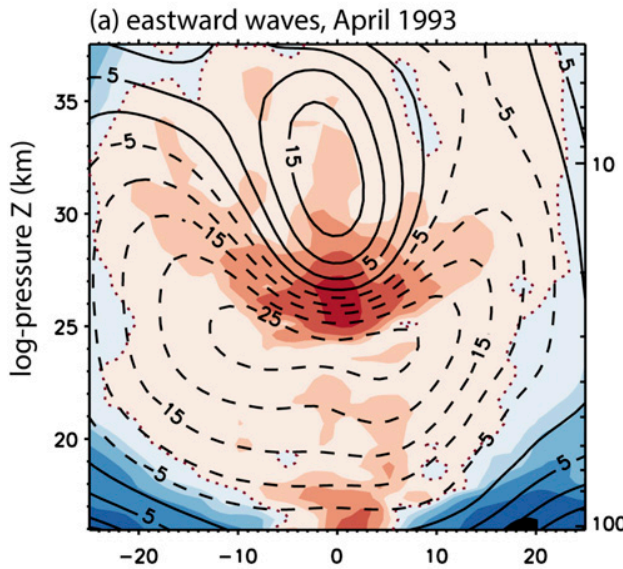

(c) eastward waves, April 1994

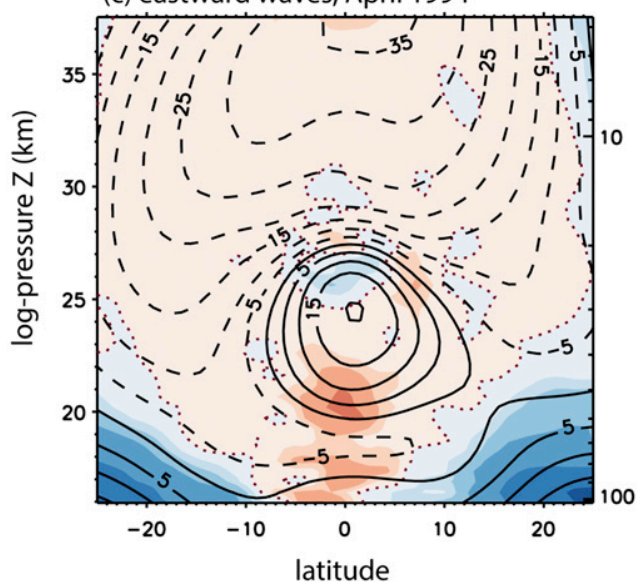

(b) westward waves, April 1993

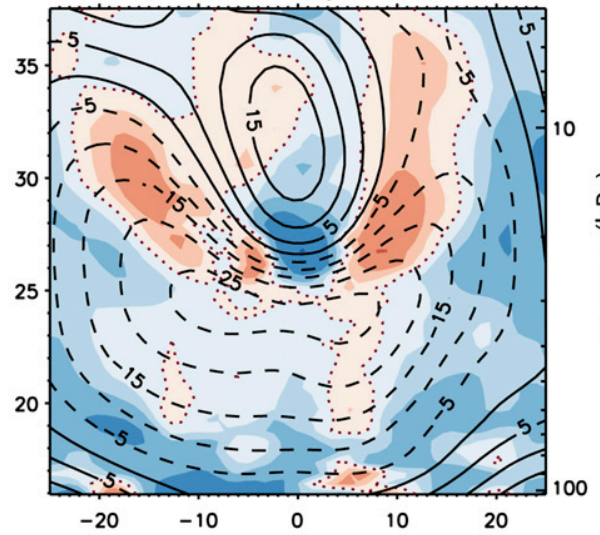

(d) westward waves, April 1994

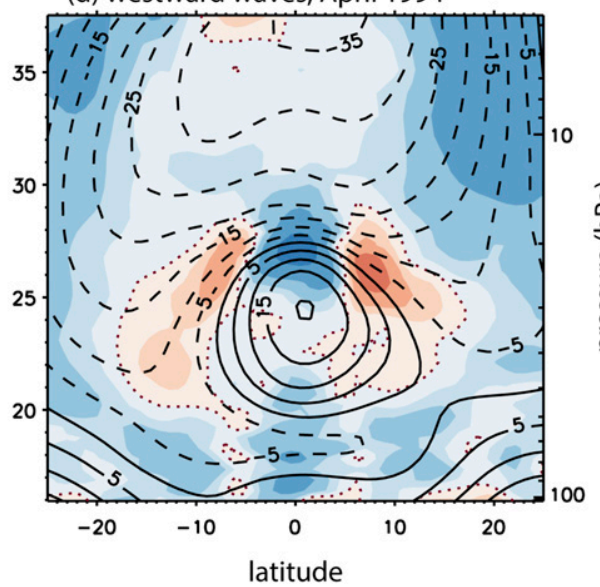

FIG. 9. Accelerations $\left(\mathrm{m} \mathrm{s}^{-1}\right.$ day $\left.^{-1}\right)$ during the descending West phase of April 1993 due to (a) eastward-propagating equatorial waves and (b) westward-propagating equatorial waves summed over wavenumbers $k=1-15$. (d)-(f) As in (a)-(c), but for the descending East phase of April 1994. Note the variable contour intervals in the color scale for the acceleration. Contours of the monthly averaged zonal-mean zonal wind $\left(\mathrm{m} \mathrm{s}^{-1}\right)$ are superimposed.

to phase velocities from -5 to $-15 \mathrm{~m} \mathrm{~s}^{-1}$, somewhat slower than the corresponding westward-traveling waves during the West phase (cf. Figs. 8a and $8 \mathrm{~b}$ for $\omega<0)$. The acceleration produced by the westwardtraveling waves during April 1994 (Fig. 9d) resembles very closely the pattern seen in the composite of Fig. 7 d, which includes all waves, as expected from the fact that eastward-propagating waves produce negligible accelerations in the descending East phase (Fig. 9c). In summary, eastward- and westwardpropagating equatorial waves produce accelerations of comparable magnitude during the descending West phase of the QBO in WACCM-110L, whereas in the descending East phase only westward-propagating equatorial waves play a role.

\section{d. Identification of the equatorial waves}

The nature of the resolved waves that contribute to the momentum budget of the QBO in WACCM-110L can be examined via coherence analysis of the wave fields present in each QBO phase. We again use the method of Hayashi (1971), this time applied to wavenumbers $k>0$ at both positive and negative frequencies. Figure 10 shows the coherence amplitude and phase of the horizontal eddy velocity $u^{\prime}$ for wavenumber $k=2$ in the range of frequency $0<\omega<0.3 \mathrm{cpd}$ (eastward periods longer than 3.3 days) during the descending West phase of April 1993; the range of frequency chosen selects waves that contribute strongly to the westerly acceleration in the descending West phase (cf. Fig. 8a). The amplitude and phase pattern seen in Fig. 10 is 


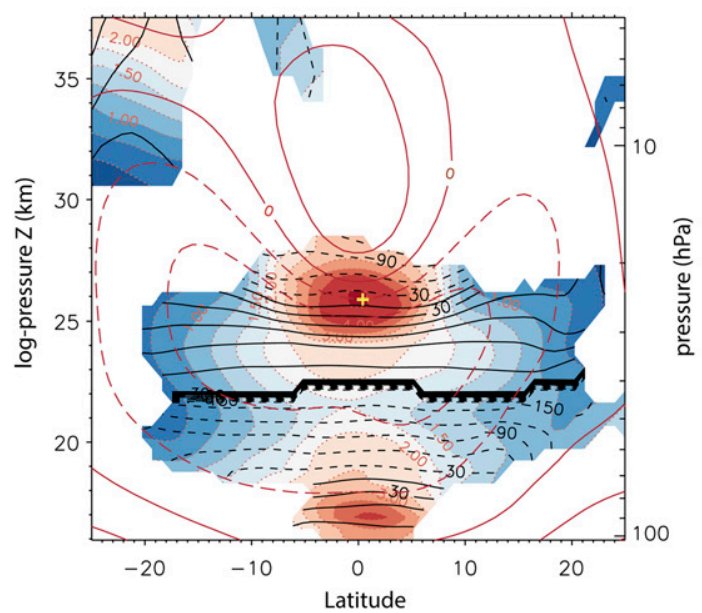

$\mathrm{ms}^{-1}$ 6.00 5.00 4.00 3.50 3.00 2.50 2.00 1.75 1.50 1.25

FIG. 10. Amplitude (color shading and labels on dotted red contours; $\mathrm{m} \mathrm{s}^{-1}$ ) and phase (black contours; degrees relative to the base point) of the $k=2$ eastward-propagating eddy zonal velocity field $u^{\prime}\left(\mathrm{m} \mathrm{s}^{-1}\right)$ during April 1993, at frequencies $0<\omega<0.3 \mathrm{cpd}$, calculated from a coherence-squared analysis (see text for details). The zonal-mean zonal wind averaged over the month is shown as red contours, at $10 \mathrm{~m} \mathrm{~s}^{-1}$ intervals, with the zero-wind contour labeled. The base point for the coherence analysis is denoted by the plus sign. Results are omitted where the significance of the coherence-squared statistic is $<90 \%$.

characteristic of a Kelvin wave modulated by the background zonal-mean zonal wind, which is denoted by the superimposed red contours in the figure. Note, in particular, how the vertical wavelength increases and the amplitude profile broadens in the region of easterly winds between 20 and $25 \mathrm{~km}$, whereas the wavelength decreases and the amplitude profile contracts in the westerly shear zone above $25 \mathrm{~km}$. There is no coherent oscillation above about $28 \mathrm{~km}$, which indicates that $k=$ 2 waves of frequency $0<\omega<0.3 \mathrm{cpd}$ are absorbed in the shear zone. Examination of other zonal wavenumbers that contribute strongly to the EP flux divergence during this month $(k=1-5$; cf. Fig. 8 a) reveals similar behavior, except that $k=1$ shows coherence above the shear zone, suggesting that these waves are not completely dissipated therein. This is consistent with the spectrum shown in Fig. 8, where $k=2-4$ contribute considerably stronger acceleration than does $k=1$. We also carried out the coherence analysis on the meridional component of the eddy velocity $v^{\prime}$ (not shown) and found it to be small compared to $u^{\prime}$, as expected for Kelvin waves.

In WACCM-110L, Kelvin waves dominate the largescale wave forcing of the West phase of the QBO throughout the stratosphere. In the foregoing we have emphasized the behavior of the descending West and East phases near $30 \mathrm{hPa}$ because it highlights interesting differences between the acceleration patterns due to eastward- and westward-propagating waves in the middle stratosphere. In the lowermost stratosphere, forcing of the QBO by large-scale waves is mainly westerly (cf. Fig. 7) and is due to longer-period Kelvin waves. For example, the spectral distribution of EP flux divergence in April 1994 at $19-20 \mathrm{~km}(\sim 50 \mathrm{hPa})$ is dominated by Kelvin waves of $k=1-3$ and periods of 5-20 days (not shown). The presence of Kelvin waves over a broad range of zonal wavenumbers during the descending West phase is consistent with theory (e.g., Holton and Lindzen 1972) and with previous modeling results (e.g., Giorgetta et al. 2002, 2006; Kawatani et al. 2010; Richter et al. 2014b).

On the other hand, the westward-propagating waves that are present in both the descending West and East phases of the QBO have received less attention in previous studies. For example, both Giorgetta et al. (2002, 2006) and Kawatani et al. (2010) remark that mixed RG waves play a minor role in the descending East phases and highlight instead the importance of smaller-scale inertia-gravity waves, either parameterized or explicitly resolved. However, a recent study by Krismer and Giorgetta (2014, their Fig. 10c) shows an acceleration pattern due to westward-propagating waves during a composite descending West phase that resembles what is shown here in Fig. 9b. What is the nature of these waves?

Figure 11 shows a coherence analysis of the amplitude and phase of $u^{\prime}$ and $v^{\prime}$ for westward-traveling waves of frequencies $-0.3<\omega<0 \mathrm{cpd}$ at $k=8$ during the descending West phase of April 1993 and the descending East phase of April 1994. The choice of frequency band is again motivated by Fig. 8 , in this case for the waves that contribute most strongly to the easterly acceleration. As in Fig. 10, the superimposed red contours in Fig. 11 denote the average zonal-mean zonal wind for the month. Wavenumber 8 is chosen here because it produces the largest accelerations attributable to westward-traveling waves, per Fig. 8; however, other wavenumbers in the range $k=4-12$ display similar structures and patterns of significance. The wave shown in Fig. 11 has the structure of a narrow, equatorially trapped $\mathrm{RG}$ wave, as evidenced by the equatorially symmetric pattern of the $v^{\prime}$ component and antisymmetric pattern of the $u^{\prime}$ component. The vertical wavelength, $\lambda_{z}$, near the amplitude maximum at $27-28 \mathrm{~km}$ is short, about $4-5 \mathrm{~km}$.

How do the structures shown in Fig. 11 compare with theoretical predictions for equatorially trapped waves? The vertical wavelength of RG waves can be obtained from the dispersion relation (Andrews et al. 1987, chapter 4): 


\section{$\mathrm{Coh}^{2}$ amp, phase $(90 \%)$ \\ $k=8$ westward $(-0.3<\omega<0 \mathrm{cpd})$}

(a) U’ April 1993

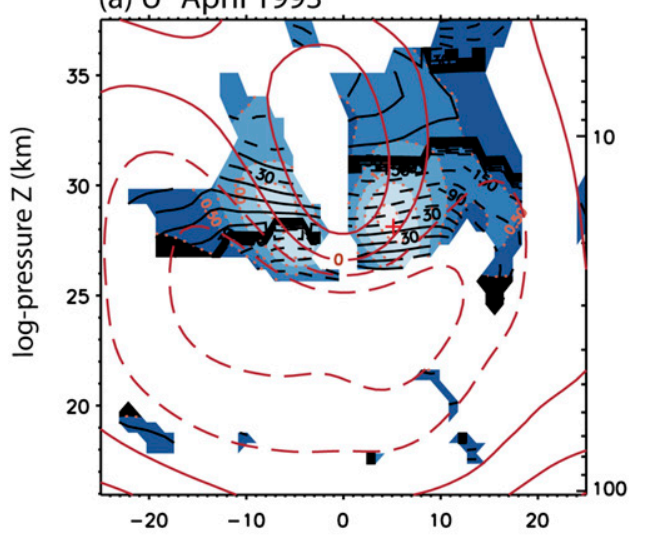

(c) U' April 1994

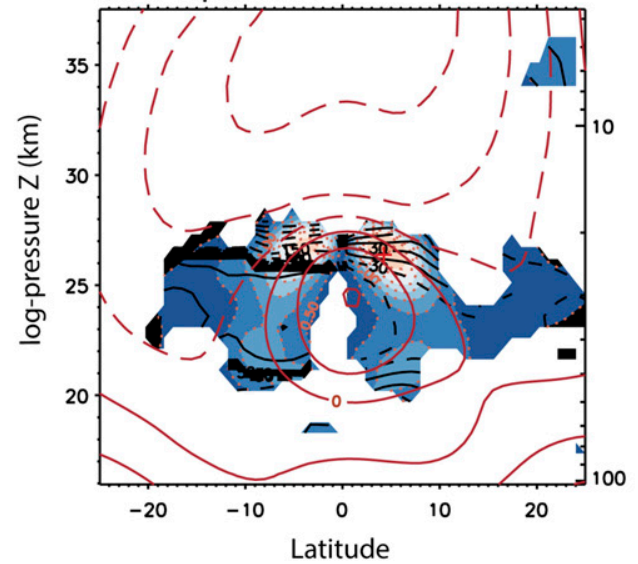

(b) V' April 1993

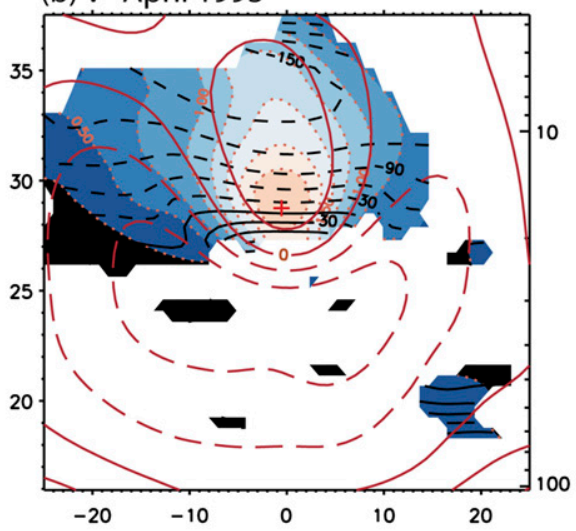

(d) V' April 1994

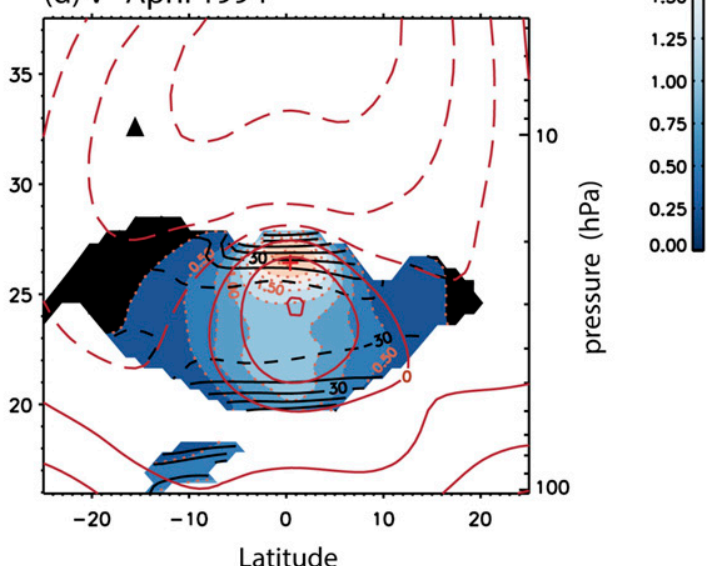

FIG. 11. As in Fig. 10, but for the westward-propagating $u^{\prime}$ and $v^{\prime}$ eddy velocity fields $\left(\mathrm{m} \mathrm{s}^{-1}\right)$ at $k=8$ and frequencies $-0.3<\omega<0$ cpd during (a),(b) April 1993 and (c),(d) April 1994.

$$
m=-\operatorname{sgn}\left(\omega^{+}\right) \frac{N}{\omega^{+2}}\left(\beta+\omega^{+} k\right),
$$

where $\omega^{+}=\omega-k U$ is the intrinsic frequency, $\omega$ is the ground-based frequency, $k$ is the zonal wavenumber, $\beta$ is the Rossby parameter at the equator, $N$ is the BruntVäisälä frequency, and $U$ is the background, zonal-mean zonal wind. From inspection of Fig. $8, \omega \sim-0.15 \mathrm{cpd}$ at $k=8$ in both April 1993 and April 1994. The choice of an appropriate value of $U$ is somewhat ambiguous; from Fig. 11, $U$ varies from -10 to $10 \mathrm{~m} \mathrm{~s}^{-1}$ over the range of latitude and altitude where the amplitude of the waves is largest. However, if we set $U=0$ and use $\omega=-0.15 \mathrm{cpd}$, $k=8$, and $N=0.02 \mathrm{~s}^{-1}$ in Eq. (1), we obtain $\lambda_{z}=$ $2 \pi / m=4 \mathrm{~km}$, which is consistent with the structures shown in Fig. 11. Along the same lines, the theoretical latitudinal structure of equatorially trapped waves varies as $\exp \left(-y^{2} / L_{e}^{2}\right)$, where $y$ is the latitude, and

$$
L_{e}=\sqrt{2 N /(\beta m)}
$$

is the meridional $e$-folding scale. Using $m=2 \pi / \lambda_{z}$ with $\lambda_{z}=4 \mathrm{~km}$ in Eq. (2) yields $L_{e} \sim 1100 \mathrm{~km}$, or about $10^{\circ}$ of latitude, which is also consistent with the meridional scale of the waves in Fig. 11. The agreement with theoretical expectations supports the conclusion that the waves that produce most of the (explicitly resolved) easterly accelerations in WACCM-110L are indeed RG waves. We note that these RG waves are present, not just in the midstratosphere (as shown in Fig. 11) but at any level where the QBO westerlies are latitudinally "narrow" and the spectral distribution of their EP flux divergence is dominated by zonal wavelengths in the range $k=4-12$ (as in Fig. 8). The association of the waves with narrow equatorial westerlies provides a clue to their origin, as shown next. 


\section{$\operatorname{div}(\mathrm{F})$ due to westward waves $\left(\mathrm{ms}^{-1}\right.$ day $\left.^{-1}\right)$}

(a) April 1993

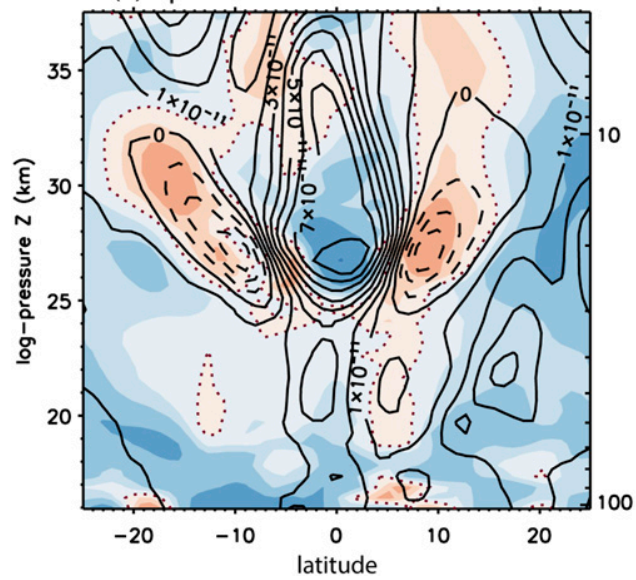

(b) April 1994

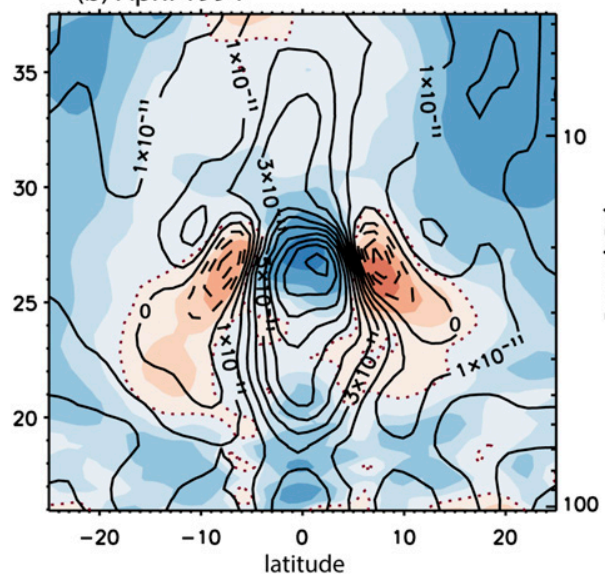

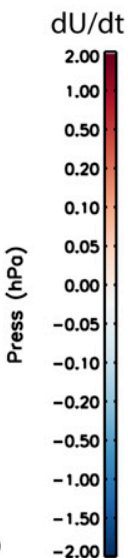

FIG. 12. Acceleration $\left(\mathrm{m} \mathrm{s}^{-1}\right.$ day $\left.^{-1}\right)$ due to westward-propagating equatorial waves $(\omega<0)$ summed over wavenumbers $k=1-15$ during (a) April 1993 and (b) April 1994. The zonal-mean barotropic vorticity gradient, Eq. (3), is superimposed as black contours with contour interval of $10^{-11} \mathrm{~m}^{-1} \mathrm{~s}^{-1}$.

\section{Instability of the QBO westerly jet}

A closer look at the RG wave structures shown in Fig. 11 suggests that they are generated locally. In the descending West phase of April 1993, the phase of the wave in Figs. 11a and 11b decreases with altitude, as expected for an upward-propagating westward RG wave. The wave structure is coherent between the amplitude maximum near 28 and $35 \mathrm{~km}$, where westerly winds begin to weaken, but there is no coherent oscillation below the amplitude maximum, where the waves would encounter a critical level in the easterly wind region. Thus, the RG wave during April 1993 appears to be generated in situ, near the "nose" of the westerly jet at $28 \mathrm{~km}$ and propagates into the westerly wind region above. In the descending East phase of April 1994, on the other hand, the phase of the wave increases with altitude from about $22 \mathrm{~km}$ to the altitude of maximum amplitude near $28 \mathrm{~km}$ (Figs. 11c,d), which implies downward group propagation into the westerly wind region below. The occurrence of downward group propagation between 22 and $28 \mathrm{~km}$ indicates that the RG waves in the descending East phase are also generated locally near $28 \mathrm{~km}$. The apparent in situ generation of these RG waves suggests that they might arise from instabilities of the background state.

Examination of the barotropic vorticity gradient,

$$
\zeta_{y}=\left(\beta-U_{y y}\right)
$$

where $U$ is the zonal-mean zonal wind, $y$ is the distance from the equator, and $\beta$ is the equatorial Rossby parameter, provides support for the presence of instability. Figure 12 shows the acceleration (color shading) due to all westward-propagating waves $(\omega<0)$ in April of 1993 and 1994 with $\zeta_{y}$ superimposed as line contours. The presence of narrow QBO westerly jets (cf. Fig. 9) gives rise to strong, positive vorticity gradients in the immediate neighborhood of the equator, which become negative over a range of latitudes between about $5^{\circ}$ and $15^{\circ}$ north and south of the equator. A reversal of $\zeta_{y}$ is a necessary condition for barotropic instability, which is clearly met by the QBO westerly jets in the present simulation. Incidentally, we have also examined the behavior of the quasigeostrophic potential vorticity gradient,

$$
Q_{y}=\zeta_{y}-\frac{1}{\rho} \frac{\partial}{\partial z}\left(\rho \frac{f^{2}}{N^{2}} \frac{\partial U}{\partial z}\right)
$$

where $\rho$ is the density, and found that it behaves almost identically to $\zeta_{y}$. We conclude that it is the strong meridional curvature of $U$ that produces reversals of $\zeta_{y}$ and $Q_{y}$.

The possibility that the QBO westerly jet is barotropically unstable was raised by Hamilton (1984). He calculated the vorticity gradient, Eq. (3), using observations from some 20 individual stations and found reversals of $\zeta_{y}$ on both sides of the equator during a descending East phase (his Fig. 7) and a descending West phase (his Fig. 8) that are generally consistent with what is shown in Fig. 12 here. Hamilton also noted the analytical results of Andrews and McIntyre (1976, their Figs. 1 and 2), who derived EP flux divergence patterns 
for RG waves that resemble closely what is shown in Fig. 9b and 9d, and suggested that these patterns could arise from large-scale instabilities, such as barotropic instability. Hamilton et al. (2001) found evidence of reversals of $\zeta_{y}$ in their simulation of the QBO using the Geophysical Fluid Dynamics Laboratory's SKYHI model that were "persistent features that follow the westerly jet descent," as in the present simulation.

Shuckburgh et al. (2001) studied the impact of the QBO on transport and mixing using reanalysis data from the European Centre for Medium-Range Weather Forecasts (ECMWF) and concluded that barotropic instability of the QBO westerlies could be the cause of the subtropical mixing they found to be present during the QBO West phase, and that such mixing was "associated with eddies with zonal wavenumbers 6-10 centered about $10^{\circ}$ from the equator," which is strikingly consistent with both the scales of the RG waves found here and the locations of positive EP flux divergence regions due to these waves (cf. Figs. 8 and 12). Hitchman and Huesmann (2009) have also documented reversals of $\zeta_{y}$ associated with the QBO westerlies, in this case using ERA-40 data (see their Fig. 4a and related discussion). Yao and Jablonowski (2015) conducted a series of experiments using different numerical "dynamical cores" to test the sensitivity of the simulated QBO to the method employed for numerical solution of the equations of motion. They found indications of both inertial (Dunkerton 1981) and barotropic instabilities in at least some of the dynamical cores that they tested. In WACCM-110L we seldom find any evidence that the condition for inertial instability, $f\left(f-U_{y}\right)<0$, is met and conclude that inertial instability is not important in our simulation of the QBO.

Apart from the studies cited above, there does not appear to be much mention in the literature of instabilities associated with the QBO westerly jet. Nevertheless, the evidence presented in the studies cited seems robust and agrees well with what is found in the present simulation. This raises the question why, to our knowledge, the presence of barotropic instability has not been noted in previous work with numerical models other than those of Hamilton et al. (2001) and Yao and Jablonowski (2015). A possible reason is the requirement for high vertical and latitudinal resolution needed to simulate the RG waves produced by the instability. Recall that these waves have typical vertical wavelengths of $4-5 \mathrm{~km}$ and meridional $e$-folding scales of $10^{\circ}$, which, depending on implicit numerical dissipation, would require vertical resolution better than $1 \mathrm{~km}$ and a couple of degrees of latitude. However, most all models that produce realistic QBO simulations meet these requirements. In fact, the very-high-horizontal-resolution model of Kawatani et al. (2010) also has extremely fine vertical resolution, $300 \mathrm{~m}$, but these authors report that westward-propagating equatorial waves provide at most $10 \%$ of the easterly acceleration in the QBO (cf. their Fig. 6). On the other hand, in the results reported by Giorgetta et al. (2006, their Fig. 8b) and especially by Krismer and Giorgetta (2014, their Fig. 10c), there are acceleration patterns associated with the QBO westerly jet that are consistent with what is shown in our Figs. 9b and $9 \mathrm{~d}$. Nonetheless, the presence of these acceleration patterns is not emphasized in either of the cited studies.

We note that the practice of averaging vertical acceleration profiles within a few degrees of the equator to show the relationship between the zonal-mean zonal wind and forcing by various types of wave could produce misleading results if too wide an average is taken in latitude. From Fig. 9, the easterly acceleration due to RG waves is concentrated within less than $5^{\circ}$ of the equator and is flanked by regions of positive acceleration. If a near-equatorial average extending much beyond $\pm 5^{\circ}$ is taken, the averaged acceleration will tend to vanish. This is illustrated in Fig. 13 for the descending East phase of April 1994 in WACCM-110L. In a $\pm 5^{\circ}$ average (Fig. 13a), the easterly acceleration associated with RG is large, comparable to the acceleration due to parameterized GW. Note also that this acceleration is completely consistent, both in its magnitude and relation to the descending easterlies, with that shown by Krismer and Giorgetta (2014, their Fig, 12b), who average their results over $\pm 5^{\circ}$. On the other hand, when the average is taken over $\pm 10^{\circ}$ (Fig. 13b), the contribution due to $\mathrm{RG}$ waves almost vanishes (while that due to GWs is enhanced because GW accelerations are actually stronger away from the equator; cf. Fig.7e). It is interesting in this regard that the acceleration profiles shown by Kawatani et al. (2010) as well as the observational estimates of Ern et al. (2014) are averaged over $\pm 10^{\circ}$.

It should be noted, in any event, that the role of the RG waves documented here appears to be not so much to force easterly zonal winds but rather to modify the meridional profile of the zonal wind, such as to reduce its meridional curvature and remove the barotropic instability. If this is the case, one might wonder why the accelerations due to $R G$ waves are persistent in WACCM-110L, being found in both the descending West and East phases always in association with regions where the sign of $\zeta_{y}$ reverses, which are commonplace at nearly all times in the domain of the simulated QBO. Hamilton (1984) and Hamilton et al. (2001) have highlighted the longevity of regions of reversed $\zeta_{y}$ in observations and the SKYHI model. In particular, Hamilton (1984) notes that the persistence of regions of negative $\zeta_{y}$ suggests that "in-situ barotropic instability may not 
Acceleration profiles, April 1994
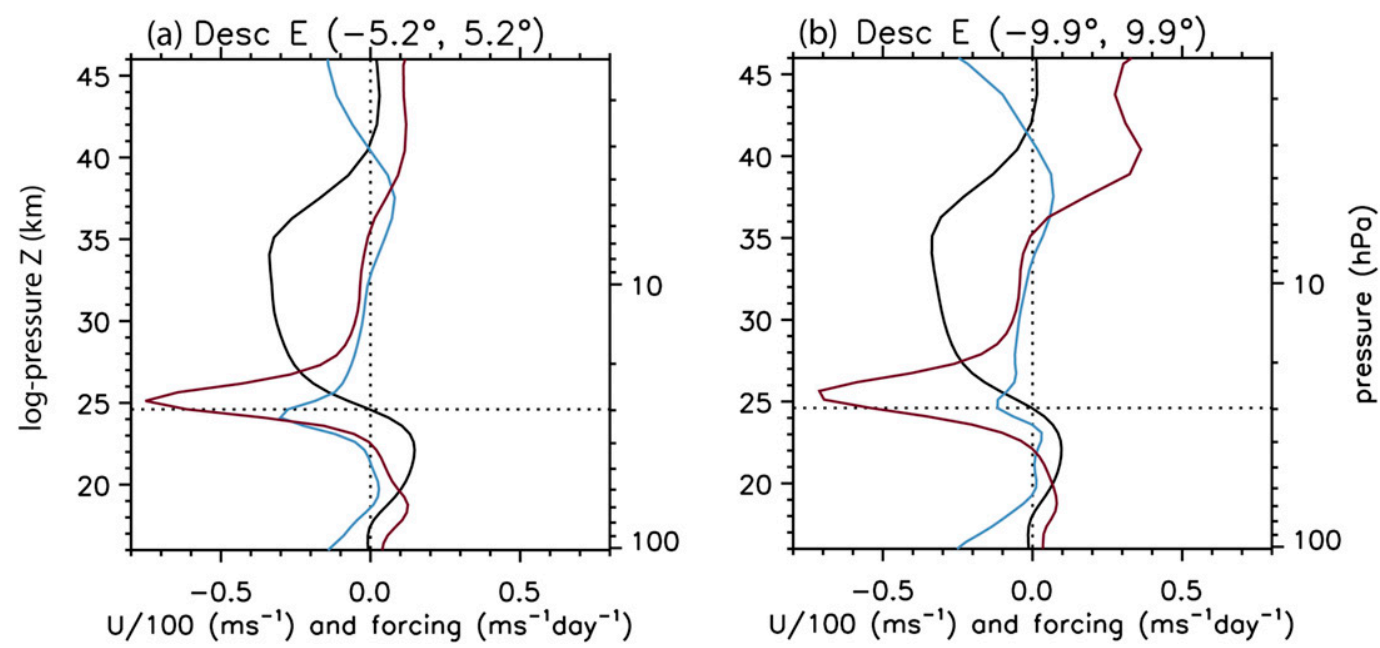

FIG. 13. Vertical profiles of acceleration $\left(\mathrm{m} \mathrm{s}^{-1} \mathrm{day}^{-1}\right)$ due to parameterized $\mathrm{GW}$ drag (red) and resolved equatorial RG waves (blue) averaged over (a) $\pm 5.2^{\circ}$ and (b) $\pm 9.9^{\circ}$ during the descending East phase of April 1994. The vertical profile of the zonal-mean zonal wind averaged over the corresponding latitude range and multiplied by $10^{-2}$ is shown in black.

act as a very efficient mechanism in smoothing the mean flow [latitude] profile." Similarly, Andrews and McIntyre (1976) remark that they expect "such instabilities would tend to occur intermittently."

The fact that instability of the westerly QBO jet is a hallmark of the WACCM-110L simulation raises the following question: what maintains its unstable meridional profile in the face of dissipation by the RG waves? Turning again to Fig. 9, it is clear that the acceleration pattern due to the westward-propagating RG waves acts to decelerate the westerly jet close to the equator and to accelerate it away from the equator. Unopposed, such accelerations, whose magnitude can be as large as 0.25 $0.5 \mathrm{~m} \mathrm{~s}^{-1}$ day $^{-1}$, should be able to reduce substantially the curvature of the westerly jet, by broadening its profile, in less than a month. However, these accelerations do not act unopposed, as seen in the composites for the total acceleration in the descending West and East phases shown in Fig. 7. The total (net) acceleration is westerly in the descending West phase and easterly in the descending East phase with smooth meridional profiles, as noted earlier. Thus, other waves, including both parameterized GW and Kelvin waves, produce accelerations that maintain the narrow (and unstable) westerly jets against dissipation by the RG waves.

\section{Summary and conclusions}

This study has documented several aspects of the behavior of the QBO simulated in WACCM-110L, a high vertical resolution version of NCAR's Whole Atmosphere Community Climate Model. The model is run with horizontal resolution of $0.95^{\circ} \times 1.25^{\circ}$ (latitude $\times$ longitude) and vertical resolution of $500 \mathrm{~m}$ between the top of the boundary layer and $10 \mathrm{hPa}$. Above $10 \mathrm{hPa}$, vertical resolution decreases gradually, to $\sim 1.5 \mathrm{~km}$ at $1 \mathrm{hPa}$ and $3 \mathrm{~km}$ at the top of the model (Fig. 1). We show that the enhanced vertical resolution throughout the troposphere and the lower and middle stratosphere produces a global climatology whose biases with respect to ERAI are comparable to or smaller than those found in the standard, 70-level version of WACCM (Mills et al. 2017). Furthermore, the enhanced vertical resolution in WACCM-110L produces an internally generated QBO that compares well with ERAI as regards the period, amplitude, and phase progression (Figs. 4 and 5), although the amplitude tends to be somewhat larger than in ERAI. The need for high resolution, in particular high vertical resolution, has been found to be a necessary condition for simulating a QBO in numerous previous studies (e.g., Giorgetta et al. 2002, 2006; Kawatani et al. 2010; Krismer and Giorgetta 2014; Geller et al. 2016; Anstey et al. 2016; Holt et al. 2016) This is the case regardless of whether the horizontal resolution is also very high $\left(<1^{\circ}\right)$ or somewhat coarser $\left(1^{\circ}-2^{\circ}\right)$, as is typical of models used for longer integrations.

Most arguments regarding high vertical resolution in simulations of the QBO have focused on the need to simulate explicitly Kelvin waves of period longer than 
15-20 days, whose vertical wavelength is short (a few kilometers) and which contribute substantially to westerly accelerations in the lower stratosphere (e.g., Giorgetta et al. 2002, 2006; Richter et al. 2014b; Anstey et al. 2016). These slow waves are also present in WACCM-110L, and account for the westerly accelerations seen near $50 \mathrm{hPa}$ in the composite of Fig. $7 \mathrm{~d}$ and in the specific example of April 1993 (Fig. 9c). In addition, the results presented here suggest that high vertical resolution is also necessary to simulate properly RG waves of short vertical wavelength that are apparently excited by barotropic instability of the QBO westerly jet. These RG waves are prominent in regions where the curvature of the westerly jet is large and reversals of the zonal-mean barotropic vorticity gradient, Eq. (3), occur in the neighborhood of the equator (cf. Figs. 9 and 12).

The possibility that the QBO westerly jet is unstable has been discussed in the literature (Andrews and McIntyre 1976; Hamilton 1984; Shuckburgh et al. 2001) but, aside from the studies of Hamilton et al. (2001) and Yao and Jablonowski (2015), has not been emphasized within the context of numerical modeling, even though indications of EP flux divergence patterns consistent with what we find here may be seen in several numerical modeling studies (e.g., Krismer and Giorgetta 2014). Averaging accelerations due to equatorial waves over more than $\pm 5^{\circ}$ of latitude will tend to obscure the forcing due to the RG waves excited by the instability (Fig. 13) and might account for why it was not reported by Kawatani et al. (2010), whose simulations were carried out with horizontal $\left(<1^{\circ}\right)$ and vertical $(300 \mathrm{~m})$ resolution even higher than used in the present study, or by Ern et al. (2014) in their observational study.

The acceleration patterns due to RG waves in WACCM-L110 suggest that these waves act to reduce the meridional curvature of the westerly jet, which would tend to eliminate reversals in the zonal-mean vorticity gradient and to neutralize the instability of the jet. Thus, RG waves in WACCM-L110 do not appear to play a role in forcing the downward progression of the QBO but tend instead to counteract the unstable westerly jet profile produced by the Kelvin waves and parameterized gravity waves that do force the downward propagation of the oscillation. Note that the QBO westerlies in WACCM-110L remain unstable throughout much of the stratosphere most of the time, which is consistent with what Hamilton (1984) and Hamilton et al. (2001) inferred from observations and modeling. Evidently, the forcing due to Kelvin waves and parameterized mesoscale gravity waves maintains the unstable profile against dissipation by RG waves in WACCM-110L.
If barotropic instability is indeed a prominent feature of the QBO westerly jet, then this result has important implications for transport in the tropics. That transport associated with instability might indeed be substantial is highlighted by the study of Shuckburgh et al. (2001). These authors used ECMWF reanalysis data to study isentropic transport and mixing in the tropics and found that, when the QBO winds are westerly, mixing is inhibited near the equator and enhanced in the subtropics. They argue that the regions of strong mixing coincide with the locations where the barotropic vorticity gradient is negative and suggest that they arise from barotropic instability. Shuckburgh et al. show, furthermore, that the mixing associated with the QBO westerlies is due to waves of zonal wavenumber $6-10$, which agrees well with what is found here (Fig. 8). Any such mixing is expected to produce a signature in suitably long-lived tracers that have strong meridional gradients in the subtropics. The impact of RG waves on the distribution of chemical species near the equator in WACCM-110L will be the subject of a separate study.

Acknowledgments. The National Center for Atmospheric Research is sponsored by the U.S. National Science Foundation. WACCM is a component of the Community Earth System Model (CESM), which is supported by NSF and the Office of Science of the U.S. Department of Energy. Computing resources were provided by NCAR's Climate Simulation Laboratory, sponsored by NSF and other agencies. This research was enabled by the computational and storage resources of NCAR's Computational and Information Systems Laboratory (CISL). All simulations were carried out on the Yellowstone high-performance computing platform (CISL 2012).

\section{REFERENCES}

Alexander, M. J., and D. A. Ortland, 2010: Equatorial waves in High Resolution Dynamics Limb Sounder (HIRDLS) data. J. Geophys. Res., 115, D24111, https://doi.org/10.1029/ 2010JD014782.

Andrews, D. G., and M. E. McIntyre, 1976: Planetary waves in horizontal and vertical shear: The generalized Eliassen-Palm relation and the mean zonal acceleration. J. Atmos. Sci., 33, 2031-2048, https://doi.org/10.1175/1520-0469(1976)033<2031: PWIHAV $>2.0 . \mathrm{CO} ; 2$.

- J. R. Holton, and C. B. Leovy, 1987: Middle Atmosphere Dynamics. Academic Press, 489 pp.

Anstey, J. A., and T. G. Shepherd, 2014: High-latitude influence of the quasi-biennial oscillation. Quart. J. Roy. Meteor. Soc., 140, 1-21, https://doi.org/10.1002/qj.2132.

, J. F. Scinocca, and M. Keller, 2016: Simulating the QBO in an atmospheric general circulation model: Sensitivity to resolved and parameterized forcing. J. Atmos. Sci., 73, 1649-1664, https://doi.org/10.1175/JAS-D-15-0099.1. 
Baldwin, M. P., and Coauthors, 2001: The quasi-biennial oscillation. Rev. Geophys., 39, 179-229, https://doi.org/10.1029/ 1999RG000073.

Beres, J. H., R. R. Garcia, B. A. Boville, and F. Sassi, 2005: Implementation of a gravity wave source spectrum parameterization dependent on the properties of convection in the Whole Atmosphere Community Climate Model (WACCM). J. Geophys. Res., 110, D10108, https://doi.org/10.1029/ 2004JD005504.

Bergman, J. W., and M. L. Salby, 1994: Equatorial wave activity derived from fluctuations in observed convection. J. Atmos. Sci., 51, 3791-3806, https://doi.org/10.1175/1520-0469(1994) $051<3791:$ EWADFF $>2.0 . \mathrm{CO} ; 2$.

Calvo, N., and R. R. Garcia, 2009: Wave forcing of the tropical upwelling in the lower stratosphere under increasing concentrations of greenhouse gases. J. Atmos. Sci., 66, 3184-3196, https://doi.org/10.1175/2009JAS3085.1.

CISL, 2012: Yellowstone: IBM iDataPlex /FDR-IB. Computational and Information Systems Laboratory, http://n2t.net/ark:/85065/ d7wd3xhc

Cohen, N. Y., E. P. Gerber, and O. Bühler, 2013: Compensation between resolved and unresolved wave driving in the stratosphere: Implications for downward control. J. Atmos. Sci., 70, 3780-3798, https://doi.org/10.1175/JAS-D-12-0346.1.

,-- , and $\longrightarrow$, 2014: What drives the Brewer-Dobson circulation? J. Atmos. Sci., 71, 3837-3855, https://doi.org/10.1175/ JAS-D-14-0021.1.

Coy, L., P. A. Newman, S. Pawson, and L. R. Lait, 2017: Dynamics of the disrupted 2015/16 quasi-biennial oscillation. J. Climate, 30, 5661-5674, https://doi.org/10.1175/JCLI-D-16-0663.1.

Danabasoglu, G., S. C. Bates, B. P. Briegleb, S. R. Jayne, M. Jochum, W. G. Large, S. Peacock, and S. G. Yeager, 2012: The CCSM4 ocean component. J. Climate, 25, 1361-1389, https://doi.org/10.1175/JCLI-D-11-00091.1.

Dee, D. P., and Coauthors, 2011: The ERA-Interim reanalysis: Configuration and performance of the data assimilation system. Quart. J. Roy. Meteor. Soc., 137, 553-597, https://doi.org/ $10.1002 /$ qj. 828 .

Dunkerton, T. J., 1981: On the inertial stability of the equatorial middle atmosphere. J. Atmos. Sci., 38, 2354-2364, https://doi.org/ 10.1175/1520-0469(1981)038<2354:OTISFT $>2.0 . C O ; 2$.

— lation and the stratopause semiannual oscillation. J. Geophys. Res., 102, 26107-26116, https://doi.org/10.1029/96JD03678.

Ern, M., and P. Preusse, 2009a: Wave fluxes of equatorial Kelvin waves and QBO zonal wind forcing derived from SABER and ECMWF temperature space-time spectra. Atmos. Chem. Phys., 9, 3957-3986, https://doi.org/10.5194/acp-9-3957-2009.

$\longrightarrow$, and — 2009b: Quantification of the contribution of equatorial Kelvin waves to the QBO wind reversal in the stratosphere. Geophys. Res. Lett., 36, L21801, https://doi.org/ 10.1029/2009GL040493.

— , and Coauthors, 2014: Interaction of gravity waves with the QBO: A satellite perspective. J. Geophys. Res. Atmos., 119, 2329-2355, https://doi.org/10.1002/2013JD020731.

Garcia, R. R., T. J. Dunkerton, R. S. Lieberman, and R. Vincent, 1997: Climatology of the semiannual oscillation of the tropical middle atmosphere. J. Geophys. Res., 102, 26 019-26032, https://doi.org/10.1029/97JD00207.

Geller, M. A., and Coauthors, 2016: Modeling the QBOImprovements resulting from higher model vertical resolution. J. Adv. Model. Earth Syst., 8, 1092-1105, https://doi.org/ 10.1002/2016MS000699.
Giorgetta, M. A., E. Manzini, and E. Roeckner, 2002: Forcing of the quasi-biennial oscillation from a broad spectrum of atmospheric waves. Geophys. Res. Lett., 29, https://doi.org/ 10.1029/2002GL014756.

,,,--- M. Esch, and L. Bengston, 2006: Climatology and forcing of the quasi-biennial oscillation in the MAECHAM5 model. J. Climate, 19, 3882-3901, https://doi.org/10.1175/ JCLI3830.1.

Hamilton, K., 1984: Mean wind evolution through the quasibiennial cycle in the tropical lower stratosphere. J. Atmos. Sci., 41, 2113-2125, https://doi.org/10.1175/1520-0469(1984) 041<2113:MWETTQ>2.0.CO;2.

_ R. J. Wilson, and R. S. Hemler, 2001: Spontaneous stratospheric QBO-like oscillations simulated by the GFDL SKYHI general circulation model. J. Atmos. Sci., 58, 3271-3292, https://doi.org/10.1175/1520-0469(2001)058<3271:SSQLOS $>$ 2.0.CO;2.

Hayashi, Y., 1971: A generalized model of resolving disturbances into progressive and retrogressive waves by space Fourier and time cross-spectral analyses. J. Meteor. Soc. Japan, 49, 125128, https://doi.org/10.2151/jmsj1965.49.2_125.

Hitchman, M. H., and A. S. Huesmann, 2009: Seasonal influence of the quasi-biennial oscillation on stratospheric jets and Rossby wave breaking. J. Atmos. Sci., 66, 935-946, https://doi.org/ 10.1175/2008JAS2631.1.

Holland, M. M., D. A. Bailey, B. P. Briegleb, B. Light, and E. Hunke, 2012: Improved sea ice shortwave radiation physics in CCSM4: The impact of melt ponds and black carbon. J. Climate 25, 1413-1430, https://doi.org/10.1175/JCLI-D-11-00078.1.

Holt, L. A., M. J. Alexander, L. Coy, A. Molod, W. Putman, and S. Pawson, 2016: Tropical waves and the quasi-biennial oscillation in a 7-km global climate simulation. J. Atmos. Sci., 73, 3771-3783, https://doi.org/10.1175/JAS-D-15-0350.1.

Holton, J. R., and R. S. Lindzen, 1972: An updated theory of the quasi-biennial cycle of the tropical stratosphere. J. Atmos. Sci. 29, 1076-1080, https://doi.org/10.1175/1520-0469(1972) 029<1076:AUTFTQ>2.0.CO;2.

— , and H.-C. Tan, 1980: The influence of the quasi-biennial oscillation on the global circulation at $50 \mathrm{mb}$. J. Atmos. Sci., 37, 2200-2208, https://doi.org/10.1175/1520-0469(1980)037<2200: TIOTEQ $>2.0 . \mathrm{CO} ; 2$.

Hoskins, B. J., 1982: The mathematical theory of frontogenesis. Annu. Rev. Fluid Mech., 14, 131-151, https://doi.org/10.1146/ annurev.fl.14.010182.001023.

Hurrell, J. M., and Coauthors, 2013: The Community Earth System Model: A framework for collaborative research. Bull. Amer. Meteor. Soc., 94,1339-1360, https://doi.org/10.1175/BAMS-D12-00121.1.

Julian, P., 1975: Comments on the determination of significance levels in the coherence statistic. J. Atmos. Sci., 32, 836-837, https://doi.org/10.1175/1520-0469(1975)032<0836:COTDOS $>$ 2.0.CO;2.

Kawatani, Y., K. Sato, T. J. Dunkerton, S. Watanabe, S. Miyahara, and M. Takahashi, 2010: The roles of equatorial trapped waves and internal inertia-gravity waves in driving the quasi-biennial oscillation. Part I: Zonal mean wave forcing. J. Atmos. Sci., 67, 963-980, https://doi.org/10.1175/2009JAS3222.1.

_ J. N. Lee, and K. Hamilton, 2014: Interannual variations of stratospheric water vapor in MLS observations and climate model simulations. J. Atmos. Sci., 71, 4072-4085, https://doi.org/ 10.1175/JAS-D-14-0164.1.

Kim, Y.-H., and H.-Y. Chun, 2015a: Contributions of equatorial wave modes and parameterized gravity waves to the tropical 
QBO in HadGEM2. J. Geophys. Res. Atmos., 120, 1065-1090 https://doi.org/10.1002/2014JD022174.

$\longrightarrow$, and $—, 2015 \mathrm{~b}$ : Momentum forcing of the quasi-biennial oscillation by equatorial waves in recent reanalyses. At mos. Chem. Phys., 15, 6577-6587, https://doi.org/10.5194/ acp-15-6577-2015.

Kinnison, D. E., and Coauthors, 2007: Sensitivity of chemical tracers to meteorological parameters in the MOZART-3 chemical transport model. J. Geophys. Res., 112, D20302, https://doi.org/10.1029/2006JD007879.

Kodera, K., M. Chiba, and K. Shibata, 1991: A general circulation model study of the solar and QBO modulation of the stratospheric circulation during the Northern Hemisphere winter. Geophys. Res. Lett., 18, 1209-1212, https://doi.org/10.1029/ 91GL01610.

Krismer, T. R., and M. A. Giorgetta, 2014: Wave forcing of the quasi-biennial oscillation in the Max Planck Institute Earth System Model. J. Atmos. Sci., 71, 1985-2006, https://doi.org/ 10.1175/JAS-D-13-0310.1.

Lawrence, D. M., and Coauthors, 2011: Parameterization improvements and functional and structural advances in version 4 of the Community Land Model. J. Adv. Model. Earth Syst., 3 M03001, https://doi.org/10.1029/2011MS00045.

Lindzen, R. S., 1981: Turbulence and stress owing to gravity wave and tidal breakdown. J. Geophys. Res., 86, 9707-9714, https:// doi.org/10.1029/JC086iC10p09707.

McCormack, J. P., S. D. Eckermann, and T. F. Hogan, 2015: Generation of a quasi-biennial oscillation in a NWP model using a stochastic gravity wave drag parameterization. Mon. Wea. Rev., 143, 2121-2147, https://doi.org/10.1175/MWR-D-14-0028.1.

Meinshausen, M., and Coauthors, 2011: The RCP greenhouse gas concentrations and their extensions from 1765 to 2300 . Climatic Change, 109, 213-241, https://doi.org/10.1007/ s10584-011-0156-z.

Mills, M. J., and Coauthors, 2017: Radiative and chemical response to interactive stratospheric sulfate aerosols in fully coupled CESM1(WACCM). J. Geophys. Res. Atmos., 122, $13061-$ 13 078, https://doi.org/10.1002/2017JD027006.

Moss, R. H., and Coauthors, 2010: The next generation of scenarios for climate change research and assessment. Nature, 463, 747756, https://doi.org/10.1038/nature08823.

Osprey, S. M., N. Butchart, J. R. Knight, A. A. Scaife, K. Hamilton, J. A. Anstey, V. Schenzinger, and C. Zhang, 2016: An unexpected disruption of the atmospheric quasi-biennial oscillation. Science, 353, 1424-1427, https://doi.org/10.1126/ science.aah4156.

Park, M., and Coauthors, 2017: Variability of stratospheric reactive nitrogen and ozone related to the QBO. J. Geophys. Res. Atmos., 122, 10 103-10 118, https://doi.org/10.1002/2017JD027061.

Richter, J. H., F. Sassi, and R. R. Garcia, 2010: Toward a physically based gravity wave source parameterization in a general circulation model. J. Atmos. Sci., 67, 136-156, https://doi.org/ 10.1175/2009JAS3112.1.

-, A. Solomon, and J. T. Bacmeister, 2014a: Effects of vertical resolution and nonorographic gravity wave drag on the simulated climate in the Community Atmosphere Model, version 5. J. Adv. Model. Earth Syst., 6, 357-383, https://doi.org/ 10.1002/2013MS000303.

,$- \ldots$, and $-2014 \mathrm{~b}$ : On the simulation of the quasibiennial oscillation in the Community Atmosphere Model, version 5. J. Geophys. Res. Atmos., 119, 3045-3062, https:// doi.org/10.1002/2013JD021122.

Sander, S. P., and Coauthors, 2006: Chemical kinetics and photochemical data for use in atmospheric studies. Jet Propulsion Laboratory Publ. 06-2, 523 pp., https://jpldataeval.jpl.nasa.gov/ pdf/JPL_15_AllInOne.pdf.

Shuckburgh, E., W. Norton, A. Iwi, and P. Haynes, 2001: Influence of the quasi-biennial oscillation on isentropic transport and mixing in the tropics and subtropics. J. Geophys. Res., 106, 14327-14337, https://doi.org/10.1029/2000JD900664.

Strahan, S. E., L. D. Oman, A. R. Douglas, and L. Coy, 2015: Modulation of Antarctic vortex composition by the quasibiennial oscillation. Geophys. Res. Lett., 42, 4216-4223, https:// doi.org/10.1002/2015GL063759.

Taylor, K. E., D. Williamson, and F. Zwiers, 2000: The sea surface temperature and sea ice concentration boundary conditions for AMIP II simulations. Program for Climate Model Diagnosis and Intercomparison Rep. 60, Lawrence Livermore National Laboratory, 24 pp., https://pcmdi.llnl.gov/report/ ab60.html.

Yao, W., and C. Jablonowski, 2015: Idealized quasi-biennial oscillations in an ensemble of dry GCM dynamical cores. J. Atmos. Sci., 72, 2201-2226, https://doi.org/10.1175/JAS-D-14-0236.1.

Zhang, G. J., and N. A. McFarlane, 1995: Sensitivity of climate simulations to the parameterization of cumulus convection in the Canadian Climate Centre general circulation model. Atmos.-Ocean, 33, 407-446, https://doi.org/10.1080/ 07055900.1995 .9649539 . 